NBER WORKING PAPER SERIES

\title{
STOCHASTIC TECHNICAL PROGRESS, NEARLY SMOOTH TRENDS AND DISTINCT BUSINESS CYCLES
}

\author{
Julio J. Rotemberg \\ Working Paper 8919 \\ http://www.nber.org/papers/w8919 \\ NATIONAL BUREAU OF ECONOMIC RESEARCH \\ 1050 Massachusetts Avenue \\ Cambridge, MA 02138 \\ May 2002
}

I wish to thank Russell Cooper, Peter Ireland, John Leahy, N. Gregory Mankiw, Serena Nag and Martin Solá for helpful suggestions and the Harvard Business School Division of Research for research support. The views expressed herein are those of the author and not necessarily those of the National Bureau of Economic Research.

(C) 2002 by Julio J. Rotemberg. All rights reserved. Short sections of text, not to exceed two paragraphs, may be quoted without explicit permission provided that full credit, including $\mathbb{C}$ notice, is given to the source. 
Stochastic Technical Progress, Nearly Smooth Trends and Distinct Business Cycles Julio J. Rotemberg

NBER Working Paper No. 8919

May 2002

JEL No. E3, O4

\begin{abstract}
This paper investigates whether it is possible to entertain simultaneously two attractive views about US GDP. The first is that long term growth in US GDP is attributable to an empirically plausible specification of random technical progress. The second is that deviations of GDP from a fitted smooth "trend" are mostly attributable to shocks that have only temporary effects, so that they are unrelated to the shocks to technical progress that lead to long term growth. The paper shows that these two views are not incompatible by constructing a model where stochastic technical progress (whose properties are calibrated to fit some features of US data) has essentially no effect on suitably detrended time series of GDP. The paper also studies variations in wedges between price and marginal cost that are capable of giving rise to these transitory movements.
\end{abstract}

\author{
Julio J. Rotemberg \\ Graduate School of Business \\ Harvard University \\ Morgan Hall \\ Soldiers Field \\ Boston, MA 02163 \\ and NBER \\ jrotemberg@hbs.edu
}


This paper investigates whether it is possible to entertain simultaneously two attractive views about US GDP. The first is that long term growth in US GDP is attributable to an empirically plausible specification of random technical progress. The second is that deviations of GDP from a fitted smooth "trend" are mostly attributable to shocks that have only temporary effects, so that they are unrelated to the shocks to technical progress that lead to long term growth. The paper shows that these two views are not incompatible by constructing a model where technical progress has essentially no effect on suitably detrended time series of GDP.

To demonstrate this, I first compute artificial "trends" that capture how output responds to an empirically plausible process for technical progress. I then construct artificial GDP series by summing these "trends" to a "cyclical" component of GDP that is due to disturbances whose effect is only transitory. The key result of the paper is that the detrending of these artificial GDP series yields series that are very close to the "cyclical" series and thus essentially independent of the shocks that cause long term growth. In particular, the correlation of the detrended series and the "cyclical" series is about .94, while the correlation of changes in the detrended series and the changes in GDP induced by technical progress is only about .05 .

The key implication of these findings is that it may be possible to provide a reasonably complete account of the "cyclical" fluctuations one obtains by detrending GDP without giving an important role to the shocks that cause long term growth. This further implies that it is possible for short term fluctuations to be due principally due to movements towards or inwards from the production possibility frontier. In other words, the separation between growth and cycles is consistent with the idea that short run fluctuations result mainly from variations in the extent to which the economy operates efficiently. Short run output reductions, in this view, would occur mainly when the social marginal cost of producing output falls relative to the benefits that would accrue if this output were produced. It is important to stress, however, that growth and cycles can perfectly well be distinct even if both are efficient so that nothing in this paper establishes that variations in efficiency cause business 
cycles.

The conclusion that shocks to technical progress can be uncorrelated with cyclical fluctuations appears different in spirit from one of the important conclusions of the real business cycle (RBC) literature. Since Prescott (1986), that literature has stressed that persistent changes in technological opportunities can have important business cycle effects. Indeed, Prescott (1986) shows that a stochastic process for technical progress with attractive empirical properties leads to fluctuations around a fitted trend whose variance is about the same as the variance of actual fluctuations around an identically constructed trend. This literature has thus argued that temporary departures of output from trend may mostly be due to the forces that also lead to long term growth. By contrast, this paper seeks to establish that it is equally possible for the forces that lead to long term growth to be essentially independent of those that lead to short term fluctuations around a stochastic trend. It might be asked how both of these statements can be true simultaneously, particularly because the model of individual behavior that I employ is quite similar to that of Prescott (1986). The reason such contrasting statements are possible is that the stochastic process followed by technical progress in Prescott (1986) is quite different from the one I consider here.

Prescott (1986) lets technological opportunities follow a first order autoregression that is close to a random walk. He chooses this specification because it corresponds closely to the time series properties of the Solow residual. As has been pointed numerous times, however, forces other than technical progress affect short term changes in the Solow residual. In particular, short run changes in aggregate demand or labor supply can affect Solow residuals if, either alone or in combination, there are departures from marginal cost pricing, there are variations in labor effort that lead to mismeasurement of the labor input or there are increasing returns to scale. A second kind of problem with using a random walk for technical progress is that it leads to counterfactual predictions for the short-term evolution of macroeconomic variables (see for example, Cogley and Nason 1995 and Rotemberg and Woodford 1996).

Here I consider a very different kind of process for technical progress, one that is inspired 
by Mansfield (1968) because it lets innovations diffuse slowly through the economy. The idea is that the typical shock that ultimately leads to a large increase in technical opportunities initially has only a negligible effect on these opportunities. This shock is thus followed by a protracted period where the innovation is refined and adopted.

It is important to stress that technological discoveries that diffuse slowly through the economy can still have short run consequences. In particular, the discovery of a technical innovations that is expected to raise the long run level of output creates wealth effects even if it has no impact on the current ability to produce output. As stressed by Manuelli (2000), the resulting increase in wealth tends to increase both the consumption of goods and the consumption of leisure, and the latter depresses current output. ${ }^{1}$ The question, then, is whether these wealth effects have quantitatively important effects on short run changes in aggregate activity.

The size of these effect obviously depends on the stochastic process governing the way technology diffuses through the economy. The process I use in this paper is designed to ensure that the long-term movements in GDP induced by stochastic technical progress have some common features with the trend component of GDP obtained using the technique described in Rotemberg (2000). In effect, I force the process of technological diffusion to have two properties in common with these data. First, a positive shock to technical progress leads to a protracted period of ever increasing GDP growth, with the maximum growth of GDP taking place about 60 quarters after the shock. Second, I ensure that the standard deviation of the innovation in the long-term level of GDP caused by shocks to technical progress equals .011. This equals the corresponding standard deviation obtained from the fitted trend described

\footnotetext{
${ }^{1}$ Helpman and Trajtenberg (1998) consider a different mechanism through which technical discoveries are capable of depressing current output. The take total labor supply as exogenous but suppose that these discoveries only affect the production process if the number of workers devoted to $R \& D$ is increased so that the discovery is implemented. The result is that discoveries lower the physical output of goods as workers are moved from production to R\&D. Whether the value of goods and services measured by GDP would fall as a result of such a shift then depends on intricacies of national income accounting.

Another difference between Helpman and Trajtenberg (1998) and the approach pursued here is that they have in mind a very large aggregate shock. They thus do not calibrate the size of this shock on the basis of time series evidence on the innovations in the long run level of GDP.
} 
above. ${ }^{2}$ Obviously, neither of these requirements imposes any constraints on the short-term impact of shocks to technical progress.

The short run effects of long run progress also depends on one's model of the economy, including the values of its parameters. I carry out this study in the context of two relatively standard equilibrium models. The first model I consider is the familiar one-sector growth model which has been studied extensively in the real business cycle literature. This model is worth considering first because it is well known that it induces large short-term movements in output for the stochastic processes governing technical progress that are usually assumed in macroeconomics. By contrast, for the stochastic process I consider here, these short run movements are much smaller.

The second model I consider is a two-sector model where only labor is needed to produce capital goods but capital and labor are productive in the consumption goods sector. I then suppose, as do Greenwood, Hercowitz and Huffman (1988), that technical progress takes the form of increasing the efficiency of capital goods. They show that, for certain parameters of the process governing these technological changes, random technical progress can lead to important short-term movements in output. Once again, these movements are much smaller for the stochastic process I consider here. Moreover, the size of these short run movements can be rendered essentially negligible by varying the parameter governing the costs of adjusting investment.

The paper proceeds as follows. The next section discusses the models while Section 2 calibrates their parameters. Section 3, then shows that equilibrium output is fairly smooth when only slowly diffusing technical progress affects output. What this means is that the wealth effects that accompany the shocks to technical progress are relatively small after all. The size of these effects is small both because the standard deviation of long run GDP is only .011 and because, given the way technological progress cumulates, the instantaneous effect of any given shock on GDP is considerably smaller than the long run effect.

\footnotetext{
${ }^{2}$ This standard deviation is larger but not much larger than the value of .007 that Rotemberg and Woodford (1996) estimated for the standard deviation of the innovation in long run output using a VAR containing GDP growth, linearly detrended hours worked and the ratio of consumption to GDP.
} 
Given that the wealth effects are modest, it seems reasonable to seek to remove the effects of smooth technical progress by removing a smooth trend, and I do this in Section 4. There, I construct composite series that are the sum of a series that behaves in a "cyclical" way and series obtained from computing equilibrium reactions to smooth technical progress. I rationalize the behavior of the cyclical series with variations over time in efficiency wedges, though other rationalizations would yield the same results. The reason is that, in this section, I focus only on the extent to which the difference between the composite series and a smooth trend captures the movements of the cyclical series.

Not surprisingly, these detrended series are more accurate when the parameters of the model are such that GDP reacts more smoothly to stochastic technical progress. However, this effect is very small for the parameters I consider. On the other hand, Section 5 shows that the parameters that give the smoothest response of GDP also have a less desirable effect. In particular, they imply that extremely volatile efficiency wedges are needed to explain cyclical fluctuations. Section 6 concludes.

\section{The Models}

I let the representative agent at $t$ maximize a utility function of the form:

$$
E_{t} \sum_{j=0}^{\infty} \beta^{j}\left[\log \left(C_{t+j}\right)-V\left(H_{t+j}\right)\right]
$$

where $C_{t}$ represents consumption at $t, H_{t}$ represents hours of work at $t$ and $V$ is an increasing convex function. To simplify, I assume that there is a unit mass of consumers so that $C$ and $H$ represent both the per capita and the aggregate levels of consumption and hours.

I suppose that the real wage $W_{t}$ equals a markup $\mu_{t}^{L}$ times the marginal rate of substitution between leisure and consumption. In other words,

$$
\frac{W_{t}}{C_{t}}=\mu_{t}^{L} V^{\prime}\left(H_{t}\right)
$$

This equation says that the increase in utility obtained by consuming the proceeds of working an extra hour equal $\mu_{t}^{L}$ times the utility costs of the extra hour of work. When labor is competitively supplies $\mu^{L}=1$ but labor market distortions can raise $\mu^{L}$ above this level. 
Where the models differ is in their production structure. In the one-sector model I consider, output of individual firm $i, Y_{t}^{i}$ is given by

$$
Y_{t}^{i}=B\left(z_{t} H_{t}^{i}\right)^{\alpha}\left(K_{t}^{i}\right)^{1-\alpha}-\Phi
$$

where $z_{t}$ is an index of technological diffusion at time $t, B, \alpha$ and $\Phi$ are parameters while $H_{t}^{i}$ and $K_{t}^{i}$ are the amounts of labor and capital used by firm $i$ at $t$. I include the fixed cost $\Phi$ to ensure that firms earn no profits, at least on average, even when their price is above marginal cost. I thus suppose that $\Phi$ is zero when I consider the perfectly competitive version of the model.

Let $R_{t}$ be the price in terms of consumption goods that firms must pay at $t$ to rent one unit of capital for use during $t$. Firms then set

$$
\begin{aligned}
\alpha B z_{t}\left(\frac{K_{t}^{i}}{z_{t} H_{t}^{i}}\right)^{1-\alpha} & =\mu_{t}^{G} W_{t} \\
(1-\alpha) B\left(\frac{z_{t} H_{t}^{i}}{K_{t}^{i}}\right)^{\alpha} & =\mu_{t}^{G} R_{t}
\end{aligned}
$$

where $\mu_{t}^{G}$ is the markup of price over marginal cost in the case where firms take $W_{t}$ and $R_{t}$ as given. With perfect competition this is identically equal to one. Below, I also consider situations where competition is imperfect and the wedge $\mu_{t}^{G}$ varies over time.

I simplify the analysis by supposing that purchasers see all the goods produced by the different producers as perfect substitutes. ${ }^{3}$ This means that, supposing all firms end up using the same inputs and there are $N_{t}$ firms, aggregate output $Y_{t}$ is

$$
Y_{t}=B\left(z_{t} H_{t}\right)^{\alpha} K_{t}^{1-\alpha}-N_{t} \Phi
$$

With identical individual output levels, (4) and (5) also hold when the individual values $K_{t}^{i}$ and $H_{t}^{i}$ are replaced by the aggregates $K_{t}$ and $H_{t}$. Given the perfect substitutes assumption, profits in terms of consumption goods are

$$
B\left(z_{t} H_{t}^{i}\right)^{\alpha}\left(K_{t}^{i}\right)^{1-\alpha}-\Phi-W_{t} H_{t}^{i}-R_{t} K_{t}^{i}=B\left(z_{t} H_{t}^{i}\right)^{\alpha}\left(K_{t}^{i}\right)^{1-\alpha}\left[1-\frac{1}{\mu_{t}^{G}}\right]-\Phi .
$$

\footnotetext{
${ }^{3}$ This is by no means essential, as shown in Rotemberg and Woodford (1991). They consider the case where substitutability is imperfect and this fits better with the lack of perfect competition that rationalizes the wedge $\mu$.
} 
If free entry ensures that profits are zero, this equation together with (3) implies that individual firm's output $Y_{t}^{i}$ equals $\Phi /\left(\mu_{t}-1\right)$. Using (3) and (6) this implies that the number of firms and aggregate output equal, respectively

$$
\begin{aligned}
N_{t} & =\left(\mu_{t}^{G}-1\right) Y_{t} / \Phi \\
Y_{t} & =\frac{B}{\mu_{t}^{G}}\left(z_{t} H_{t}\right)^{\alpha} K_{t}^{1-\alpha} .
\end{aligned}
$$

Equation (8) obviously holds also under perfect competition even though individual firm output and the number of firms are indeterminate in this case.

If a unit of output is bought at $t$ and invested, productive capital at $t+1$ increases by one unit. Because capital depreciates at the rate $\delta,(1-\delta)$ additional units of output also become available at $t+1$. Thus capital at $t+1, K_{t+1}$, is given by the standard accumulation equation

$$
K_{t+1}=(1-\delta) K_{t}+Y_{t}-C_{t}
$$

I consider the possibility that certain financial promises are easy to enforce and that anyone can credibly issue them. In particular, I suppose that individuals can promise to acquire capital at $t$ and disburse at $t+1$ the proceeds from both the rental of capital and the selling of the depreciated capital. This means that

$$
\frac{1}{C_{t}}=E_{t} \frac{\beta}{C_{t+1}}\left[R_{t+1}+1-\delta\right] .
$$

If the right hand side exceeded the left hand side, anyone could make a profit by obtaining one unit of consumption from a consumer and promising him a repayment of slightly less than $\left[R_{t+1}+1-\delta\right]$ in period $t+1$. Consumers would happily accept this deal as these contracts are credible. By contrast, if the right hand side were smaller than the left hand side, the entities offering such contracts would lose money and exit from this activity. Since positive amounts of capital are always used in production, (10) must hold as an equality in equilibrium.

I also consider the possibility that there are imperfections in the market governing these 
contracts. As in Cooper and Ejarque (1994), I generalize (10) so that

$$
\frac{1}{C_{t}}=\frac{1}{\mu_{t}^{F}} E_{t} \frac{\beta}{C_{t+1}}\left[R_{t+1}+1-\delta\right]
$$

An increase in the wedge $\mu^{F}$ implies that the payoffs from investing in a unit of capital must rise relative to the utility costs of foregoing a unit of consumption today. This can be interpreted as saying that the capital market is becoming more imperfect or that intermediation is becoming less efficient. In specific models of financial market imperfections, as in Bernanke, Gertler and Gilchrist (1999), this wedge depends on other economic variables including the net worth of entrepreneurs. Here I take a less specific approach and simply let $\mu^{F}$ vary exogenously.

¿From these equations, I derive three equilibrium conditions in $C_{t} / z_{t}, K_{t} / z_{t}$ and $H_{t}$. The first of these conditions follows from combining (4) (as it applies to aggregate factors) and $(2)$,

$$
\mu_{t}^{L} \mu_{t}^{G} V^{\prime}\left(H_{t}\right) H_{t}^{1-\alpha} \frac{C_{t}}{z_{t}}=\alpha\left(\frac{K_{t}}{z_{t}}\right)^{1-\alpha} .
$$

The product $\mu_{t}^{L} \mu_{t}^{G}$ is what Gali, Gertler Lopez-Salido (2002) call the gap.

The second equilibrium condition is obtained by combining (5) when it is applied to aggregate factors and (10)

$$
\frac{1}{C_{t}}=\frac{1}{\mu_{t}^{F}} E_{t} \beta \frac{1}{C_{t+1}}\left[\frac{(1-\alpha) B}{\mu_{t+1}^{G}}\left(\frac{z_{t} H_{t}}{K_{t}}\right)^{\alpha}+1-\delta\right] .
$$

The third and last equilibrium condition is not invariant to whether one is considering the case with free entry or whether one is temporarily holding the number of firms fixed. With a given number of firms $N_{t}$, using (6) in (9),

$$
\frac{K_{t+1}}{z_{t+1}} \frac{z_{t+1}}{z_{t}}=(1-\delta) \frac{K_{t}}{z_{t}}-\frac{C_{t}}{z_{t}}+B H_{t}^{\alpha}\left(\frac{K_{t}}{z_{t}}\right)^{1-\alpha}-N_{t} \Phi
$$

If, instead, one considers the case of free entry, (8) implies that

$$
\frac{K_{t+1}}{z_{t+1}} \frac{z_{t+1}}{z_{t}}=(1-\delta) \frac{K_{t}}{z_{t}}-\frac{C_{t}}{z_{t}}+\frac{B}{\mu_{t}^{G}} H_{t}^{\alpha}\left(\frac{K_{t}}{z_{t}}\right)^{1-\alpha} .
$$


These equations differ only in that increases in hours and capital have a larger effect on output (and thus on either consumption or capital accumulation) if the number of firms does not increase in the way that it would with free entry (where the size of firms is constant).

As in King, Plosser and Rebelo (1988), I study the dynamics of this model by linearizing these equations around a steady state with a constant value of $z_{t+1} / z_{t}$ and constant markups $\mu^{L}, \mu^{G}$ and $\mu^{F}$. For such a constant growth rate of technical opportunities, equations (12), (13) and (15) can be solved for steady state values of $C_{t} / z_{t}, K_{t} / z_{t}$ and $H_{t}$. Since $K_{t} / z_{t}$ is constant at such a steady state, so is $K_{t} / z_{t-1}$. Because it is more convenient to work with the state variable $K_{t} / z_{t-1}$ which is independent of current shocks, I denote the logarithmic deviations of $C_{t} / z_{t-1}, K_{t} / z_{t-1}, H_{t}$ and $z_{t} / z_{t-1}$ from their steady state values by $\tilde{c}_{t}, \tilde{k}_{t}, \tilde{h}_{t}$ and $\tilde{\gamma}_{t}$ respectively. When I consider the effects of random technical progress, I keep markups constant. Differentiating these three equations, one obtains

$$
\begin{gathered}
\tilde{c}_{t}+(1-\alpha+\xi) \tilde{h}_{t}=(1-\alpha) \tilde{k}_{t}+\alpha \tilde{\gamma}_{t} \\
\frac{\gamma K}{Y}\left(\tilde{k}_{t+1}+\tilde{\gamma}_{t}\right)-\frac{(1-\delta) K}{Y} \tilde{k}_{t}+\frac{C}{Y} \tilde{c}_{t}=(1-\alpha) \tilde{k}_{t}+\alpha\left(\tilde{h}_{t}+\tilde{\gamma}_{t}\right) \\
\frac{\mu^{F} \gamma}{\mu^{F} \gamma-\beta(1-\delta)}\left(\tilde{c}_{t+1}-\tilde{c}_{t}+\tilde{\gamma}_{t}\right)=\alpha\left(\tilde{h}_{t+1}-\tilde{k}_{t+1}+\tilde{\gamma}_{t+1}\right)
\end{gathered}
$$

where $K / Y$ and $C / Y$ represent the steady state ratios of capital and consumption to output respectively, $\gamma$ is the steady state value of $z_{t+1} / z_{t}$, and $\xi$ is the inverse Frisch elasticity of labor supply $V^{\prime \prime} H / V^{\prime}$. The steady state version of (15) implies a connection between $K / Y$ and the other parameters. In particular, it implies that $K / Y=\frac{1-C / Y}{\gamma+\delta}$.

These three equations can be used to compute the equilibrium paths of $\tilde{c}_{t}, \tilde{h}_{t}$ and $\tilde{k}_{t}$ for given expectations about the evolution of $\tilde{\gamma}$. It is worth noting that these three equations are independent of the average value of the markup $\mu^{G}$. The reasons is that, with free entry, the model is effectively one of constant returns because a proportional increase in labor and capital is accompanied by a proportional increase in the number of firms so that output rises proportionately as well.

This can be seen in (8), which can also be used to compute the extent to which output growth differs from its steady state value as a function of the variables computed above. 
Using this equation to compute $Y_{t} / Y_{t-1}$ and differentiating, the log difference between output growth at $t$ and its steady state value, which I denote by $\dot{y}_{t}$ is

$$
\dot{y}_{t}=\alpha\left(\tilde{h}_{t}-\tilde{h}_{t-1}+\tilde{\gamma}_{t}\right)+(1-\alpha)\left(\tilde{k}_{t}-\tilde{k}_{t-1}+\tilde{\gamma}_{t-1}\right)
$$

I now consider fluctuations that are caused by changes over time in $\mu^{L}, \mu^{G}$ and $\mu^{F}$. I denote I denote the logarithmic deviation of these wedges relative to their steady state values by $\tilde{\mu}_{t}^{L}, \tilde{\mu}_{t}^{G}$ and $\tilde{\mu}_{t}^{F}$ respectively. Because these fluctuations occur over relatively short intervals, I imagine that entry does not adjust so that the number of firms is fixed at the level which makes profits zero for the steady state level of the markup. Differentiating (12), (13) and (14),

$$
\begin{gathered}
\tilde{\mu}_{t}^{L}+\tilde{\mu}_{t}^{G}+\tilde{c}_{t}+(1-\alpha+\xi) \tilde{h}_{t}=(1-\alpha) \tilde{k}_{t} \\
\frac{\gamma K}{Y} \tilde{k}_{t+1}-\frac{(1-\delta) K}{Y} \tilde{k}_{t}+\frac{C}{Y} \tilde{c}_{t}=\frac{Y+N \Phi}{Y}\left((1-\alpha) \tilde{k}_{t}+\alpha \tilde{h}_{t}\right) \\
\frac{\gamma \mu^{F}}{\gamma \mu^{F}-\beta(1-\delta)}\left(\tilde{c}_{t+1}-\tilde{c}_{t}+\tilde{\mu}_{t}^{F}\right)=\alpha\left(\tilde{h}_{t+1}-\tilde{k}_{t+1}\right)-\tilde{\mu}_{t+1}^{G} .
\end{gathered}
$$

At the steady state with free entry where I evaluate the coefficients of these equations, (7) implies that $(Y+N \Phi) / Y$ equals the steady state value of $\mu^{G}$. For this reason, differentiating (6) near the steady state implies that $\tilde{y}_{t}$, the deviations of the level of output from its steady state path induced by markup variations, satisfy

$$
\tilde{y}_{t}=\mu^{G}\left[\alpha \tilde{h}_{t}+(1-\alpha) \tilde{k}_{t}\right]
$$

Equations (20), (21), (22) and (23) can be used to compute the expected paths of $\tilde{k}_{t}$, $\tilde{c}_{t}, \tilde{h}_{t}$ and $\tilde{y}_{t}$ for given current and expected future values of the $\tilde{\mu}_{t}$ 's. It is worth noting that, because the behavior of the economy can be approximated by these linear equations near a steady state, these calculations also give the extent to which capital, consumption, hours and output differ, as a result of expectations of nonzero $\tilde{\mu}$ 's, from the paths induced by expectations of $z$.

Because neither $\tilde{y}_{t}$ nor the $\tilde{\mu}_{t}$ 's are predetermined, these calculations can also be carried out in reverse so that one can compute the expected evolution of the three efficiency wedges 
from expectations about the evolution of aggregate variables. If one knows only the expected evolution of $\tilde{y}_{t}$, different expected paths for the three efficiency wedges are possible, though they imply different movements for the other variables. Since this paper is only concerned with aggregate output, I set $\tilde{\mu}_{t}^{L}$ and $\tilde{\mu}_{t}^{F}$ equal to zero and then use (20), (21), (22) and (23) to solve for the paths of current and expected future values of $\tilde{k}_{t}, \tilde{h}_{t}, \tilde{c}_{t}$ and $\tilde{\mu}_{t}^{G}$ that are consistent with particular values for current and expected future values of $\tilde{y}_{t}$. Suppose in particular that $\tilde{y}_{t}$ follows a known stochastic process, which might be described by

$$
H(L) \tilde{y}_{t}=\epsilon_{t}^{y}
$$

where $H(L)$ is a polynomial in the lag operator $L$ whose first term is equal to one. Then, (20), (21), (22) and (23) can be solved for the responses of $\tilde{k}, \tilde{c}, \tilde{y}$ as well as $\tilde{\mu}^{G}$ to $\epsilon_{t}^{y}$.

This can be interpreted this as giving the way markups react to shocks in the real economy. However, a more appealing interpretation is that this gives the moving average representation of the process for markups that generates endogenously the stochastic process for output given in (24). In particular, the instantaneous "response" of the markup to $\epsilon_{t}^{y}$ is really the size of the initial markup shock that is moving the economy away from the steady state and causing the change in output equal to $\epsilon_{t}^{y}{ }^{4}$

It is worth noting that this logic applies also to the connection between the path of expected output growth due to technical progress $\dot{y}$ and the expected path of $\tilde{\gamma}$. Equations (16), (17), (18) and (19) can just as easily be read as giving $\dot{y}$ as a function of the $\tilde{\gamma}$ (for a given level of the state variable $\tilde{k}_{t}$ ) as the reverse. Thus, one could postulate a stochastic process for $\dot{y}$ and obtain the stochastic process for $\tilde{\gamma}$ that rationalizes this evolution of $\dot{y}$ under the assumption that $\tilde{\gamma}$ is exogenous.

The second model I consider is a two-sector model in which technological progress affects only the production of investment goods. The two-sector model I consider is very similar to that of Beaudry and Portier (2000). One key difference is that unlike them but in common

\footnotetext{
${ }^{4}$ This "backwards" method of inferring shocks from the behavior of endogenous variables is used extensively in Rotemberg and Woodford (1997)
} 
with Greenwood, Hercowitz and Huffman (1988), I assume that technical progress affects only the quality of the investment goods produced in the economy. ${ }^{5}$

I suppose labor is mobile so both sectors pay the same wage. Total hours worked, $H_{t}$, are now the sum of the labor used in the investment goods sector, $H_{t}^{I}$, and the labor used in the consumption goods sector. Individual firms engaged in the production of consumption goods have the production function given by (3) except that the technological progress parameter $z_{t}$ is a constant that I set equal to one. Total production of consumption goods is thus given by

$$
C_{t}=B\left(H_{t}-H_{t}^{I}\right)^{\alpha} K_{t}^{1-\alpha}-N_{t} \Phi
$$

where $K_{t}$ is the total effective capital stock and $N_{t}$ is the number of firms producing consumption goods. With free entry, the same reasoning that leads to (8) yields

$$
C_{t}=\frac{B}{\mu_{t}^{C}}\left(H_{t}-H_{t}^{I}\right)^{\alpha} K_{t}^{1-\alpha}
$$

Capital goods are produced exclusively with labor and, because they continue to depreciate at the rate $\delta$, their level at $t+1$ satisfies

$$
K_{t+1}-(1-\delta) K_{t}=z_{t} g\left(H_{t}^{I}\right)
$$

so that technical progress affects this production function directly. For future reference, this can also be written as

$$
\frac{K_{t+1}}{z_{t}}-(1-\delta) \frac{z_{t-1}}{z_{t}} \frac{K_{t}}{z_{t-1}}=g\left(H_{t}^{I}\right)
$$

I continue to let $W_{t}$ and $R_{t}$ represent the wage and rental rate of capital in terms of consumption goods so that (2) continues to hold. Similarly, (4) and (5) continue to hold for firms producing consumption goods (with $z_{t}$ equal to one). With symmetric firms, the aggregate versions of these equations are now

$$
\begin{aligned}
\alpha B\left(\frac{K_{t}}{H_{t}-H_{t}^{I}}\right)^{1-\alpha} & =\mu_{t}^{C} W_{t} \\
(1-\alpha) B\left(\frac{H_{t}-H_{t}^{I}}{K_{t}}\right)^{\alpha} & =\mu_{t}^{C} R_{t} .
\end{aligned}
$$

\footnotetext{
${ }^{5}$ Beaudry and Portier (2000) suppose instead that it has an unpredictable effect on the future quantity of consumption goods that can be produced with a given labor and capital input.
} 
where $\mu_{t}^{C}$ is the markup in the consumer goods sector.

Combining (2), (25) and (29), we now have

$$
\left[B\left(H_{t}-H_{t}^{I}\right)^{\alpha} K_{t}^{1-\alpha}-N_{t} \Phi\right] V^{\prime}\left(H_{t}\right) \mu_{t}^{L} \mu_{t}^{C}=\alpha B\left(\frac{K_{t}}{H_{t}-H_{t}^{I}}\right)^{1-\alpha} .
$$

In the free entry case, given the equality of (25) and (26) this simplifies to ${ }^{6}$

$$
V^{\prime}\left(H_{t}\right)\left(H_{t}-H_{t}^{I}\right) \mu_{t}^{L}=\alpha
$$

Let $P_{t}^{I}$ be the price of investment goods in terms of consumption goods at time $t$ while $\mu_{t}^{I}$ is the markup of this price relative to the marginal cost of producing investment goods. Then, using (27),

$$
z_{t} P_{t}^{I} g^{\prime}\left(H_{t}^{I}\right)=\mu_{t}^{I} W_{t}
$$

An important case I consider is, once again, the case in which there is a well functioning set of contracts in which agents borrow $P_{t}^{I}$ from individuals with the purpose of buying a unit of capital at time $t$. In these contracts, the individuals who advance these funds are paid at $t+1$ the proceeds from renting this unit as well as those that result from selling the depreciated capital. For individuals to be indifferent with respect to small changes in the volume of these transactions, it must be the case that

$$
\frac{P_{t}^{I}}{C_{t}}=E_{t} \frac{\beta}{C_{t+1}}\left[R_{t+1}+(1-\delta) P_{t+1}^{I}\right]
$$

A somewhat more general alternative specification involves supposing that the individuals who advance funds at $t$ to buy one unit of capital receive only $1 / \mu_{t}^{F}$ of the proceeds from this capital. It then follows that

$$
\frac{P_{t}^{I}}{C_{t}}=\frac{1}{\mu_{t}^{F}} E_{t} \frac{\beta}{C_{t+1}}\left[R_{t+1}+(1-\delta) P_{t+1}^{I}\right] .
$$

Using (2), (25), (30) and (33), this becomes

$$
\frac{\mu_{t}^{L} \mu_{t}^{I} V^{\prime}\left(H_{t}\right)}{z_{t} g^{\prime}\left(H_{t}^{I}\right)}=E_{t} \frac{\beta(1-\alpha)}{\mu_{t}^{F} \mu_{t+1}^{C} K_{t+1}} \frac{C_{t+1}+N_{t+1} \Phi}{C_{t+1}}+E_{t} \frac{\beta(1-\delta)}{\mu_{t}^{F}} \frac{\mu_{t+1}^{L} \mu_{t+1}^{I} V^{\prime}\left(H_{t+1}\right)}{z_{t+1} g^{\prime}\left(H_{t+1}^{I}\right)}
$$

\footnotetext{
${ }^{6}$ This relationship says that, for given $\mu^{L}$, total hours can only increase when hours used to produce consumption goods actually fall. Only then can real wages rise relative to consumption so that labor supply is increased. With a fixed number of firms and variable markups, on the other hand, it is possible for $H^{I}$ and $H-H^{I}$ to rise at the same time even without changes in $\mu^{L}$.
} 
or

$$
E_{t} \frac{\beta(1-\alpha) z_{t}}{\mu_{t+1}^{C} K_{t+1}} \frac{C_{t+1}+N_{t+1} \Phi}{C_{t+1}}=\frac{\mu_{t}^{F} \mu_{t}^{L} \mu_{t}^{I} V^{\prime}\left(H_{t}\right)}{g^{\prime}\left(H_{t}^{I}\right)}-E_{t} \beta(1-\delta) \frac{z_{t}}{z_{t+1}} \frac{\mu_{t+1}^{L} \mu_{t+1}^{I} V^{\prime}\left(H_{t+1}\right)}{g^{\prime}\left(H_{t+1}^{I}\right)} .
$$

The assumption of free entry simplifies considerably the left hand side of this expression because it implies that $\frac{C_{t+1}+N_{t+1} \Phi}{C_{t+1}}$ equals $\mu_{t}^{C}$.

It is now possible to derive the steady state values for $K_{t} / z_{t-1}, H_{t}$ and $H_{t}^{I}$ for a constant value of $z_{t} / z_{t-1}$ and constant values for the markups $\mu^{C}, \mu^{I}$ and $\mu^{F}$ from the three equations (28), (32) and (35). Supposing that, at such a steady state, $\mu^{F}$ equals one the right hand side of $(35)$ is equal to $\mu^{I} V^{\prime}[\gamma-\beta(1-\delta)] /\left(g^{\prime} \gamma\right)$ where $V^{\prime}$ and $g^{\prime}$ are evaluated at the steady state values of $H_{t}$ and $H_{t}^{I}$ respectively. Using this fact, and letting $\tilde{h}_{t}^{I}$ represent the logarithmic deviation of $H_{t}^{I}$ from its steady state value, differentiation of these three equations under free entry holding the three markups constant gives

$$
\begin{gathered}
\tilde{k}_{t+1}=\frac{1-\delta}{\gamma}\left[\tilde{k}_{t}-\tilde{\gamma}_{t}\right]+\frac{g^{\prime} H^{I}}{g} \frac{\gamma+\delta-1}{\gamma} \tilde{h}_{t}^{I} \\
\left(\xi+\frac{1}{1-H^{I} / H}\right) \tilde{h}_{t}=\frac{H^{I} / H}{1-H^{I} / H} \tilde{h}_{t}^{I} \\
\tilde{k}_{t+1}=\frac{\beta(1-\delta)}{\gamma-\beta(1-\delta)}\left[\xi \tilde{h}_{t+1}+e^{I} \tilde{h}_{t+1}^{I}-\tilde{\gamma}_{t+1}\right]-\frac{\gamma}{\gamma-\beta(1-\delta)}\left[\xi \tilde{h}_{t}+e^{I} \tilde{h}_{t}^{I}\right]
\end{gathered}
$$

where $e^{I}=-g^{\prime \prime} H^{I} / g^{\prime}$. These equations can be used to obtain the paths of $\tilde{k}_{t}, \tilde{h}_{t}$ and $\tilde{h}_{t}^{I}$ as a function of the current and expected future values of $\tilde{\gamma}$.

I now turn to the computation of the log deviation of real output growth relative to the steady state on the basis of the evolution of these variables. The value of output in terms of consumption goods at $t$, which I label $Y_{t}$ equals $C_{t}+P_{t}^{I} I_{t}$ where $I_{t}$ equals $K_{t+1}-(1-\delta) K_{t}$. A Divisia index of real output growth at $t$ is thus

$$
\frac{C_{t}}{Y_{t}} \frac{d C_{t}}{C_{t}}+\frac{P_{t}^{I} I_{t}}{Y_{t}} \frac{d I_{t}}{I_{t}}
$$

where $d C_{t}$ and $d I_{t}$ represent the instantaneous changes over time in $C$ and $I$ respectively. In a steady state with constant markups and a constant rate of growth of $z$, the ratios $C / Y$ and $P^{I} I / Y$ are constant. This can be seen by noting that (27) implies that, at such a steady 
state, $K$ and $I$ grow at the rate $\gamma$ because $H^{I}$ is constant. The constancy of $H$ then, together with (26) and (29) imply that $C$ and $W$ grow at the rate $(1-\alpha) \gamma$. As a result, (33) implies that $P^{I}$ falls at the rate $\alpha \gamma$. This, in turn, implies that $P^{I} I$ rises at the rate $(1-\alpha) \gamma$ which is the same as the rate of increase of $C$.

The constancy of the ratios $C / Y$ and $P^{I} I / Y$ imply that differentiating (26) and (27), the log deviation of output growth from its steady state value, $\dot{y}_{t}$, equals

$$
\begin{gathered}
\dot{y}_{t}=\frac{C}{Y}\left[\frac{\alpha}{1-H^{I} / H}\left(\tilde{h}_{t}-\tilde{h}_{t-1}-\left(H^{I} / H\right)\left(\tilde{h}_{t}^{I}-\tilde{h}_{t-1}^{I}\right)\right)+(1-\alpha)\left(\tilde{k}_{t}-\tilde{k}_{t-1}+\tilde{\gamma}_{t-1}\right)\right]+ \\
\quad\left(1-\frac{C}{Y}\right)\left[\tilde{\gamma}_{t}+\frac{g^{\prime} H^{I}}{g}\left(\tilde{h}_{t}^{I}-\tilde{h}_{t-1}^{I}\right)\right] .
\end{gathered}
$$

As before, equations (36), (37), (38) and (39) can just as easily be used to obtain the paths of outputs and inputs on the basis of an expected path of $\tilde{\gamma}$ as they can be used to obtain the evolution of $\tilde{\gamma}$ that rationalizes a particular expected path for output.

When I consider the effect of changing markups I ignore entry and fix the number of firms at the free entry level that ensures that $C+N \Phi / C$ equals $\mu^{C}$. I denote the logarithmic deviations of $\mu_{t}^{L}, \mu_{t}^{I}, \mu_{t}^{C}$ and $\mu_{t}^{F}$ from their steady state values by $\tilde{\mu}_{t}^{L}, \tilde{\mu}_{t}^{I}, \tilde{\mu}_{t}^{C}$ and $\tilde{\mu}_{t}^{F}$ respectively. Differentiating (28), (31) and (35) at the steady state values of $H_{t}^{I}, H_{t}$ and $K_{t} / z_{t-1}$, one obtains

$$
\begin{gathered}
\tilde{k}_{t+1}=\frac{1-\delta}{\gamma} \tilde{k}_{t}+\frac{g^{\prime} H^{I}}{g} \frac{\gamma+\delta-1}{\gamma} \tilde{h}_{t}^{I} \\
\left(\xi+\frac{1+\alpha\left(\mu^{C}-1\right)}{1-H^{I} / H}\right) \tilde{h}_{t}+\tilde{\mu}_{t}^{L}+\tilde{\mu}_{t}^{C}+(1-\alpha)\left(\mu^{C}-1\right) \tilde{k}_{t}=\left[1+\alpha\left(\mu^{C}-1\right)\right] \frac{H^{I} / H}{1-H^{I} / H} \tilde{h}_{t}^{I} \\
\left\{\tilde{k}_{t+1}+\tilde{\mu}_{t+1}^{C}+\frac{\mu^{C}-1}{\mu^{C}}[(1-\alpha)\right. \\
\beta(1-\delta)\left[\tilde{\mu}_{t+1}^{L}+\tilde{\mu}_{t+1}^{I}+\xi \tilde{h}_{t+1}+e^{I} \tilde{h}_{t+1}^{I}\right]-\gamma\left[\tilde{\mu}_{t}^{F}+\tilde{\mu}_{t}^{L}+\tilde{\mu}_{t}^{I}+\xi \tilde{h}_{t}+e^{I} \tilde{h}_{t}^{I}\right] .
\end{gathered}
$$

This allows one to solve for the effect of markup deviations on the paths of $\tilde{k}_{t}, \tilde{h}_{t}$ and $\tilde{h}_{t}^{I}$. The log deviation of the level of real output from its steady state level, $\tilde{y}_{t}$ is simply the percent by which $C_{t}+P^{I} I_{t}$ departs from the steady state value of $Y_{t}$ where $P^{I}$ represents the price of investment goods along the steady state path. This can be obtained by differentiating 
(25) (evaluated at the steady state path for $N_{t}$ ) and (27). This yields

$$
\left.\tilde{y}_{t}=\mu^{C} \frac{C}{Y}\left[\frac{\alpha}{1-H^{I} / H}\left(\tilde{h}_{t}-\left(H^{I} / H\right) \tilde{h}_{t}^{I}\right)\right)+(1-\alpha) \tilde{k}_{t}\right]+\left(1-\frac{C}{Y}\right) \frac{g^{\prime} H^{I}}{g} \tilde{h}_{t}^{I} .
$$

Equations (40), (41), (42) and (43) can be used to solve for the expected path of $\tilde{k}$, $\tilde{h}^{I}, \tilde{h}$ and $\tilde{y}$ as a function of the expected paths of $\tilde{\mu}_{t}^{L}, \tilde{\mu}^{I}, \tilde{\mu}^{C}$ and $\tilde{\mu}^{F}$. This means that a particular stochastic process for $\tilde{y}$ of the form (24) can be rationalized by a number of different stochastic processes for the four markup deviations.

\section{Calibration}

There are two quite different types of parameters that play a role in the models I simulate. The first type are the behavioral parameters that act as coefficients in the linearizations discussed in the previous section. The second are the parameters that govern the evolution of $\tilde{\gamma}_{t}$ and the $\tilde{\mu}$ 's.

For the one-sector model, I set $\mu_{t}^{L}=\mu_{t}^{F}=1$ and choose behavioral parameters which are within the range considered in the real business cycle literature (see King, Plosser and Rebelo (1988) and King and Rebelo (1999)). They are listed on Table 1.

\section{Table 1}

Parameters for the One-Sector Model

\begin{tabular}{|c|c|c|c|c|c|c|}
\hline$\beta$ & $\xi$ & $\alpha$ & $\delta$ & $\gamma$ & $\mathrm{C} / \mathrm{Y}$ & $\mu^{G}$ \\
.99 & 1 & .7 & .03 & .01 & .7 & $1,1.4$ \\
\hline
\end{tabular}

The reason I neglect changes in $\mu^{L}$ and $\mu^{F}$ is that they do not contribute to the analysis. It should be clear, however, that changes in $\mu^{L}$ have similar effects on output than changes in $\mu^{G}$. By using suitable variations in $\mu^{L}$ while setting $\mu^{G}=1$ I would have obtained identical results.

In the case of the two-sector model, there are some additional parameters. The first of these is the value of $g^{\prime} H^{I} / g$. The steady state version of (33) implies that $g^{\prime} H^{I} / g \mu^{I}$ equals the labor share in the sector that produces investment goods $W H^{I} / P^{I} z g$. I suppose this 
share is the same as the corresponding share in the consumption good sector, namely $.7 .{ }^{7}$ The equality of the two labor shares implies that the ratio of the labor used in producing investment goods to the labor used in producing consumption goods is equal to the ratio of the revenues of the two industries. This implies in turn that $\left(H-H^{I}\right) / H$ equals the ratio of consumption spending to the value of output, which I keep equal to .7.

The last parameter that plays a role in the two-sector model is $e^{I}=-g^{\prime \prime} H^{I} / g^{\prime}$. The existence of diminishing returns in the investment goods sector ensures this is positive. Moreover, because $W / z g^{\prime}$ is the marginal cost of producing an additional unit of capital goods, $e^{I}$ is the elasticity of this marginal cost with respect to a percent increase in $H^{I}$. I experiment with various values for this parameter. One appealing aspect of considering values that are large in absolute value is that this implies that there are large costs of making investment volatile. Thus a high absolute value for this parameter plays a role similar to the assumption of adjustment costs for capital. They both imply that higher rates of growth of the capital stock are associated with higher marginal costs of increasing the capital stock by one unit.

While the behavioral parameters that I consider are relatively standard, my assumptions about the evolution of $z$ are not. What I seek is a stochastic process for $z$ such that a positive technological disturbance has, at first, only a very small effect on the availability of productive opportunities. The availability of opportunities then experiences increasingly faster growth for some time, before settling back to its normal growth rate. The idea is that even those inventions that have huge eventual effects on output have only modest instantaneous effects on the technology that is "in use".

The parameters I pick to capture this process are designed to fit some aspects of the long run movements in US GDP. In particular, I choose a stochastic process for $z$ that ensures that output satisfies some of properties of the trend in output growth that one obtains by detrending US GDP using the method of Rotemberg (2000). Figure 1 shows the evolution

\footnotetext{
${ }^{7}$ That the labor share in the consumption goods sector equals $\alpha$ follows from the fact that (4) implies that this labor share equals $\alpha(Y+N \Phi) / Y \mu$. This equals $\alpha$ because $Y+N \Phi / Y$ equals $\mu$.
} 
of the growth rate of this trend from 1947:1 to 1998:1. From a statistical point of view, this growth rate seems well described by an $\mathrm{AR}(5)$. In particular, a regression explaining trend growth with five lags of trend growth yields the following

$$
\begin{aligned}
\dot{y}_{t}^{a}= & 4.11 \dot{y}_{t-1}^{a}-6.59 \dot{y}_{t-2}^{a}+5.1 \dot{y}_{t-3}^{a}-1.86 \dot{y}_{t-4}^{a}+0.24 \dot{y}_{t-5}^{a} \\
& (.07) \quad(.27) \quad(.41) \quad(.27) \quad(.07) \quad \text { S.E. }=8.84 e-8
\end{aligned}
$$

where $\dot{y}_{t}^{a}$ is the rate of growth of trend GDP at $t$ and the constant is imprecisely estimated and insignificantly different from zero. Further lags are not statistically significant when added to this regression. As a result of rounding, the reported estimates in the above regression add up exactly to 1.0. In the absence of rounding, these estimates add up something just short of 1.0 so that the estimated process is stationary. It is thus possible to describe this process in a revealing way by displaying the moving average coefficients which describe how (trend) output growth responds to a unit impulse that takes place in the first period. ${ }^{8}$

This response in displayed in Figure 2. This figure shows that the growth rate rises steadily from the first period and reaches a maximum of 1915 after 63 quarters. The growth rate then falls back towards its steady state value, though it overshoots it as the convergence to the steady state involves damped oscillations. Since the growth rate converges, a shock of this type only has an effect on the long run level of output. The long run effect of a unit impulse is $1.25 \mathrm{e} 5$.

While this long run effect seems huge, it is important to remember that the standard deviation of the residuals in (44) is only $8.84 \mathrm{e}-8$. This means that these residuals induce a standard deviation of the innovation in the level of long run output that equals $(1.25 \mathrm{e} 5)(8.84 \mathrm{e}-$ 8) or .011. This is larger but not much larger than the value of .007 that Rotemberg and Woodford (1996) estimated for the standard deviation of the innovation in long run output

\footnotetext{
${ }^{8}$ Interestingly, the first difference of the HP trend of GDP also fits an AR(5) fairly well. Its residual is quite a bit larger, however. Its standard error equals 4e-6. Moreover, the moving average representation of this fitted process involves much stronger short run effects. The main reason I do not use the HP trend is that trend growth of GDP obtained by this method is strongly correlated with the HP cycle. It would thus not be reasonable to combine artificial trends that mimic the properties of the HP trend to cyclical series that are independent of these constructed trends.
} 
using a VAR containing GDP growth, linearly detrended hours worked and the ratio of consumption to GDP.

Given the process for output growth in (44), it is also possible to construct stochastic processes for $\tilde{\gamma}$ that rationalize this process in each of the models I consider. I carry out these calculations in order to see whether the processes for $\tilde{\gamma}$ that are computed in this way seem reasonable on a priori grounds. As I show below, they quite often are not.

Instead, I mostly focus on a process for $z$ that generates long run movements in output that are broadly consistent with these facts. In particular, I use a process such that output growth rises after a positive innovation and reaches its maximum level after about 60 quarters. At the same time, I choose the standard deviation of the shocks to $z$ in such a way that the standard deviation of the corresponding innovation in the permanent level of output equals .011.

The actual process for $\tilde{\gamma}_{t}$ I use is given by

$$
\left(1-\lambda_{1} L\right)\left(1-\lambda_{2} L\right)\left(1-\lambda_{3} L\right) \tilde{\gamma}_{t}=\epsilon_{t}^{z}
$$

where $L$ is the lag operator, the $\lambda$ 's represent three roots and $\epsilon_{t}^{z}$ is an i.i.d. variable with standard deviation $\sigma^{z}$. I suppose that $\lambda_{1}$ and $\lambda_{2}$ are complex conjugates with modulus equal to .985 and angle of \pm .02 . The use of these complex conjugates ensures that shocks which raise $z$ 's growth rate are followed by ever larger increases in this growth rate for some time. I set the value of $\lambda_{3}$ equal to .5.

The purpose of including the wedges $\mu^{L}, \mu^{C}, \mu^{F}$ and $\mu^{I}$ is to consider variables whose movements have only short term effects on GDP. For this purpose I could also have included exogenous short-run variations in productivity. In any event, the analysis above has shown that one can use variations in the wedges I considered to rationalize any stationary process for output. I thus consider variations in these variables that justify the temporary movements of output that emerge from the trend/cycle decomposition in Rotemberg (2000). Denoting my measure of temporary deviations of output from trend by $\hat{y}_{t}^{a}$, using quarterly data from 1947:1 to 1998:1, and ignoring the constant, this series appears to be well-described the 
following autoregression:

$$
\begin{aligned}
\hat{y}_{t}^{a}= & .89 \hat{y}_{t-1}^{a}+.34\left(\hat{y}_{t-1}^{a}-\hat{y}_{t-2}^{a}\right)+.15\left(\hat{y}_{t-2}^{a}-\hat{y}_{t-3}^{a}\right)+\epsilon_{t}^{a} \\
& (.025)(.068)
\end{aligned}
$$

Subsequent lags are statistically insignificant. Once again, an appealing way to describe this involves displaying the way $y^{a}$ responds to a unit impulse. This is shown in Figure 3. After increasing by one unit, such a shock leads to further small increases in output in the next two quarters. After this, cyclical output returns fairly rapidly to its mean value. Indeed, after 15 quarters the effect of the shock is almost entirely dissipated. This strong reversion towards the mean is reflected in the relatively low coefficient on lagged output in the above equation as well as in the positive coefficients on lagged output growth (which ensure that when output starts falling the level of output is pulled further back towards the mean).

In the one-sector model, I allow for only one wedge between price and social marginal cost so the stochastic process for this wedge can be recovered uniquely from (46). In the two-sector model, by contrast, I set $\mu_{t}^{L}=1$ and let the other wedges vary (though I could have obtained identical results by allowing $\mu^{L}$ to vary and fixing, for example, $\mu^{C}$ ). I do this because I am interested in analyze the effects of some key parameters on the markup variations that are needed to rationalize actual business cycles. In particular, variations in $e^{I}$, which affect the extent to which output growth responds smoothly to $\epsilon_{t}^{z}$, have implications for the type of markup variations that are needed to rationalize business cycles. To make this conceptual point, I let $\mu^{C}, \mu^{I}$ and $\mu^{F}$ be proportional to one another so that

$$
\begin{aligned}
& \tilde{\mu}_{t}^{C}=\nu^{C} \tilde{\mu}_{t}^{I} \\
& \tilde{\mu}_{t}^{F}=\nu^{F} \tilde{\mu}_{t}^{I}
\end{aligned}
$$

and I experiment with several values for $\nu^{C}$ and $\nu^{F}$. 


\section{Impulse responses from a shock to $\gamma_{z}$}

In this section, I ignore variations in the $\tilde{\mu}$ 's and concentrate on the effects of changes in $\epsilon^{z}$. I first consider the one-sector model in the case where technical progress evolves as in (45). Figure 4 shows the reaction of output growth to a unit impulse in $\epsilon_{t}^{z}$. As required, the process (45) does ensure that peak output growth occurs about 60 quarters after the shock. ${ }^{9}$

Figure 4 also shows that a one percent increase in $z$ initially lowers output by $60 \%$. Output continues to decline for a while longer before it starts rising. I found initial output declines of this sort in every model I simulated in which the process for technical progress involved a gradual rise in $z$ while also ensuring that peak output growth takes place about 60 quarters after the initial shock.

The mechanism for this finding is easy to understand, and is quite similar to that in Manuelli (2000). Large future increases in technical progress create strong current wealth effects. They thus lead the representative agent to increase his current consumption as well as his current leisure. This means, in particular, that it is rational to consume some of the existing capital stock immediately. These additional aspects of the responses to the increase in $\gamma^{z}$ can be seen in Figures 5 and 6 . These show the response of hours as well as that of $C_{t} / z_{t-1}$. Hours stay below the steady state for some time, while consumption relative to $z$ first rises and then falls. Consumption itself does not fall, however, as $z$ rises rapidly over time. The wealth effects thus ensure that a shock to technical progress starts what might be termed a recession. Interestingly, the idea that eventual technical progress initially causes output declines is found to have some empirical support in Gali (1999). ${ }^{10}$

One obtains an alternative view of the importance of wealth effects in this model if one constructs the process for $\tilde{\gamma}$ that rationalizes the output growth process given by (44). This process is depicted in Figure 7. It shows that $z$ grows abruptly in the first period. Its growth

\footnotetext{
${ }^{9}$ While the peak of growth in the figure appears to be much smaller than the peak response in Figure 2, this mostly reflects the fact that a shock that initially raises $z$ by one percent has a very different effect on the long run value of $z$ in the two cases. It raises the long run value of $z$ by about 125,000 in the case of Figure 2 while it raises by about 3200 in Figure 4.

${ }^{10}$ Rather different evidence of contractionary effects of technical progress is found in Shea (1998). However, this evidence hinges critically on heterogeneity across sectors, which is obviously absent in my model.
} 
then falls to more moderate levels only to rise again and have a local maximum after about 60 quarters. The one-quarter rise at the beginning is larger than this local maximum in $\tilde{\gamma}$. This process is intuitively unappealing. If technology in use were able to grow as abruptly as indicated in the figure, the delayed reactions shown in the figure would be difficult to rationalize.

Moreover, the process depicted in Figure 7 still leads to large wealth effects and thus large initial declines in hours worked. To see this, Figure 8 depicts the employment response to an $\epsilon^{z}$ shock which has the moving average representation given in Figure 7 . This shows that employment declines abruptly and stays low for some time, just as it did in response to shocks to (45) in Figure 5. Indeed, since the cumulative output response to a shock to (44) is about 40 times larger than that to a shock to (45), the two responses of employment are quite comparable. This means that the process in Figure 7 avoids initial declines in output not by reducing wealth effects but only by including an abrupt exogenous force that would otherwise abruptly raise output on impact.

I now turn to the two-sector model. This model has the feature that, rather realistically, it prevents agents from consuming their capital. This makes it harder for them to increase their consumption when $z$ first rises and thus has the potential for reducing the fall in the value of work that was observed in the one-sector model. The initial responses in this model turn out to depend critically on the parameter governing the curvature of the production function for investment goods $-g^{\prime \prime} H^{I} / g^{\prime}$. If one makes this parameter equal to the curvature of the production function for consumer goods, it equals $(1-\alpha)$ or .3. For this parameter value, a one percent rise in $\epsilon^{z}$ still leads to substantial instantaneous output declines in the two-sector model.

The reason is that, while it is impossible to consume capital it is still rational for agents to postpone investment until $z$ has risen further. This means that agents still let capital fall through depreciation. It also means that the labor input devoted to investment goods falls for some time. The absolute reduction in output when $\epsilon^{z}$ rises by one percent is smaller than in the one-sector model, but so is the ultimate increase in output growth when the rise in $z$ 
is fastest. The reason, of course, is that the increase in $z$ now has a smaller effect since it only affects a fraction of production.

A revealing way to compare the one and two-sector model's output responses, is to hit the two models with $\epsilon^{z}$ 's of different sizes where these sizes are chosen so that the initial reduction in output growth is the same. This is done in Figure 9. In the case of the twosector model, the responses are different for $\mu^{C}=\mu^{I}=\mu=1$ and $\mu^{C}=\mu^{I}=\mu=1.4$ so the figure shows both responses (I set the average $\mu^{F}$ equal to 1 in both cases). The Figure shows that, for this given output reduction, subsequent output growth is largest in the one-sector model. Moreover, in the two-sector model, subsequent output growth is lower when $\mu=1.4$ than under perfect competition.

This last effect is due to the fact that while my assumptions regarding free entry imply that the consumption sector effectively operates with constant returns to scale even when $\mu=1.4$, this is not true of the investment goods sector. This sector has higher returns to scale the higher is $\mu$. This means that the reductions in $H^{I}$, which result from both the wealth effect and the fact that future $H^{I}$ is much more productive than current $H^{I}$, lead to much larger reductions in output when $\mu=1.4$.

But, even when $\mu=1$, the combination of strong incentives to postpone investment and the fact that the increase in $z$ affects a smaller fraction of the economy in the two-sector model, suffice to imply that the initial decline in output looms large relative to that of the one-sector model in the case where $e^{I}=.3$. Matters are different when $e^{I}$ is increased. To show this, I consider a somewhat extreme case in which $e^{I}=60$. Figure 10 plots the resulting responses of output to a shock to $\epsilon^{z}$ for both the cases when $\mu$ is equal to 1 and 1.4 (the responses are essentially superimposed). Output still declines on impact but this effect is negligible, particularly as the cumulative output response from the shock equals about 1650 , which is roughly half the output response in the one-sector model.

The initial reductions in output are small because the initial reductions in $H^{I}$ are themselves small so that the degree of returns to scale in the investment goods sector is not important. The reason, in turn, for the fall in $H^{I}$ to be small when $e^{I}=60$ is that the 
increased curvature of $g$ implies that the marginal product of labor rises very quickly in this sector as workers are withdrawn from it. The result is that output changes are fairly smooth.

This means that one also obtains reasonable results with $e^{I}=60$ if one uses the process for trend output growth (44) to infer the stochastic process of $\tilde{\gamma}$ that gives rise to the fluctuations in $\dot{y}$. In particular, Figure 11 shows the evolution of $\tilde{\gamma}$ that is needed after a shock of one percent to (44) to rationalize this output response. The growth in $z$ in the first period is only 5 times larger than the growth in the second period and both are substantially smaller than the growth of $z$ in subsequent quarters.

I now study whether the differences in the impulse responses I have considered so far are reflected in the smoothness of growth rates of GDP induced by random draws of $\epsilon^{z}$ when $\tilde{\gamma}$ follows the process in (45). For each specification, the effect of the history of $\epsilon^{z}$ shocks on $\dot{y}$ can be written as

$$
\dot{y}_{t}=\sum_{\tau=1}^{N} \Theta_{\tau} \epsilon_{t-\tau}^{z}
$$

where the theoretical value of $N$ is generally infinite and $\Theta_{\tau}$ gives the response of output growth $\tau$ periods after the shock. The values of $\Theta_{\tau}$ obviously depends on the specification. Using the $\Theta$ 's that I derived earlier for my five specifications while truncating $N$ at 500, I construct draws of $\dot{y}$ of length 205 (which corresponds roughly to the length of available quarterly GDP series in the U.S.) by using a random number generator to obtain realizations of $\epsilon_{t}^{z}$. I then add a linear trend with a coefficient that ensures that the rate of growth of this constructed series equals .0079 , which is the rate of growth of $\dot{y}_{t}^{a} \cdot{ }^{11}$ I denote these constructed series by $\dot{y}^{z}$.

I construct 500 series of $\dot{y}^{z}$ for each specification. These specifications include the onesector model as well as the two-sector model with $e^{I}$ equal to both .3 and 60 . I also consider separately the cases where the average markup in the consumption and investment goods sectors equal 1 and 1.4. For each of the resulting $\dot{y}^{z}$ series, I compute a simple measure of smoothness. This measure is simply the mean of $\left(\dot{y}_{t}^{z}-\dot{y}_{t-1}^{z}\right)^{2}$. I compute this mean for each

\footnotetext{
${ }^{11}$ As discussed in Rotemberg (2000), these added linear trends end up fully incorporated into the estimated trends. Thus, the only function of these added trends is to make the low frequency behavior of the constructed $\dot{y}$ series be similar to that of $\dot{y}^{a}$
} 
realization of $\dot{y}^{i}$ and the first line of Table 2 shows the results of averaging this mean across all realizations.

Table 2

The Smoothness of the Constructed trends

\begin{tabular}{|l|c|c|c|c|c|}
\hline & One-sector & \multicolumn{4}{|c|}{ Two-sector } \\
\hline & & $e^{I}=.3, \mu=1$ & $e^{I}=.3, \mu=1.4$ & $e^{I}=60, \mu=1$ & $e^{I}=60, \mu=1.4$ \\
\hline $\begin{array}{l}\text { Squared second } \\
\text { difference }\end{array}$ & $7.97 \mathrm{e}-8$ & $10.3 \mathrm{e}-8$ & $23.4 \mathrm{e}-8$ & $5.39 \mathrm{e}-10$ & $5.68 \mathrm{e}-10$ \\
\hline
\end{tabular}

For purposes of comparison, the mean of $\left(\dot{y}_{t}^{z}-\dot{y}_{t-1}^{z}\right)^{2}$ would be zero if the series were a linear trend. On the other hand, the mean of the squared second difference of US GDP from $1947: 1$ to $1998: 1$ is $1.47 \mathrm{e}-4$. Thus, the constructed series are substantially smoother than actual GDP, particularly when $e^{I}$ equals 60 . As can be expected given the differences in impulse responses shown in Figure 9, the least smooth series is obtained in the two-sector model with $\mu=1.4$ and $e^{I}=.3$. But even for this series, this indicator of smoothness is nearly 1000 times smaller than for US GDP.

\section{Distinguishing Nearly Smooth Trends from Business Cycles}

Because technical progress leads to fairly smooth changes in GDP, it seems natural to ask whether removing a smooth trend allows one to accurately measure the "business cycle" when actual output consists of the sum of $y^{z}$ and a cyclical series. The method of Rotemberg (2000) seems particularly appropriate for this purpose because it ensures that the trend and the cycle do not move together over short periods of time. This orthogonality seems essential if one is supposed to extract a cycle which is known to be orthogonal to the disturbances that cause long run growth. At the same time, the method seeks to make the trend smooth while also preventing its "cycles", i.e, the deviations from trend, from being too long. It should be clear why smooth trends are desirable in the current context. The avoidance of cycles that are too long is important as well. Otherwise, one can always make the trend a straight line 
(which is maximally smooth) at the cost of incorporating changes in trend growth induced by technical progress into the measured cycle.

The cyclical series I construct have the same stochastic process as (46). Thus, I invert this process so that the cycle at $t, y_{t}^{c}$ can be written as

$$
y_{t}^{c}=\sum_{\tau=1}^{n} \theta_{\tau} \epsilon_{t-\tau}^{c}
$$

where $\epsilon_{t}^{c}$ is an i.i.d random variable with the same variance as $\epsilon_{t}^{a}$, namely, 9e-5. I generate samples (of length 205) of $y_{t}^{c}$ by setting $n=50$ and using a random number generator to produce observations of $\epsilon_{t}^{c}$. As explained above, the variations in $y_{t}^{c}$ could be due to variations in markups and indeed, one can recover the necessary variations in markups if one knows a priori that variations in certain markups are the only cause of $y_{t}^{c}$.

The series I analyze are then given by

$$
y_{t}^{m}=y_{t}^{z}+y_{t}^{c}
$$

I do not consider the five specifications I considered earlier. Rather I consider only the one-sector model, and three specifications of the two-sector model with $\mu=1.4$. In these three specifications, $e^{I}$ equals $.3,5$ and 60 respectively. For the case with $e^{I}=5$, obviously, the response of $\dot{y}$ to $\epsilon^{z}$ is intermediate in smoothness between the case where $e^{I}=.3$ and the case where it equals 60 .

In this section, I thus neglect the specifications with $\mu=1$. A reason to do this is that if the variability of cyclical output is due to symmetric variations in the $\mu$ 's around their steady state values, it is unappealing to suppose that $\mu$ falls below one. It thus makes sense to start out with values of $\mu$ above one. Of course, the requirement that $\mu$ be greater than one is consistent with the average value of $\mu$ being only negligibly higher than one as long as the fluctuations in $\mu$ are small. However, this raises the question of whether only small fluctuations in $\mu$ are needed to rationalize the size of actual cyclical fluctuations in GDP. I return to this question below.

My approach consists, once again, of drawing 500 histories of $\epsilon^{z}$ and $\epsilon^{c}$, each of which yields 205 observations on $y_{t}^{m}$. I then compute several indicators of the ease with which the 
component of output due to $z, y_{t}^{z}$ can be decomposed empirically from the component due to markup variations $y_{t}^{c}$. Before doing so, it is worth discussing briefly the connection between the properties of $y_{t}^{m}$ and U.S. GDP. The two series, obviously do not have identical statistical properties since the initial reaction to $z$ shocks in the equilibrium models is generally quite different from the initial reaction of GDP to a shock to equation (44). Still, it is worth knowing whether the $y^{m}$ series are radically different from the logarithm of GDP. For this purpose, Figure 12 displays the log of the periodogram of the log of US GDP from 1947:1 to 1998:1. For comparison with this, I also computed the periodogram for 500 realizations of $y^{m}$ by setting $e^{I}=5$ (the results for other values of $e^{I}$ are very similar). The smooth curve in the center of the displayed lines of Figure 12) contains the log of the mean values (frequency by frequency) of these power spectra. The two lines at the top and bottom are the $\log$ of the maximum and minimum realized values of power at each frequency from these 500 observations. Because these lines are quite close to one another, one can conclude that the realized histories of $y^{z}$ bear some broad similarity to the history of US GDP.

The indicators of the ease with which $y^{m}$ can be decomposed are displayed in Table 3. Most of my focus is on the results of detrending the composite series with the method of Rotemberg (2000), though I also computed some statistics with the HP filter for comparison. Except where otherwise indicated, the indicators in Table 3 are obtained by ignoring the first and last 16 observations. The reason is that it is difficult to estimate smooth trends near the boundaries of the sample.

The first indicator I consider is the mean square error of the estimated trends relative to the generated values of $y_{t}^{z}$. The first two rows show that, indeed, these MSE's are lower when the boundary observations are eliminated. This is also true when the HP filter is used to estimate the trend. Overall, the method of Rotemberg (2000) is more accurate than the HP filter. When observations at the boundary are ignored, its MSE is about two times smaller.

At the same time, the method of Rotemberg (2000) generates estimates whose error is not negligible relative to the variance of the cycle. The cycle variance from (46) is $8.08 \mathrm{e}-4$ so that, ignoring the boundaries, the MSE equals about $15 \%$ of the variance of the signal $y^{c}$. 
Not surprisingly, those specifications that generate a less smooth trend $y^{z}$ generate higher MSE's, though the differences are fairly small. When the trends are computed ignoring the boundaries, the least smooth trend has a MSE that is only about $6 \%$ higher than that of the smoothest trend.

The MSE is not ideal for understanding whether detrending recovers a useful measure of the cycle, because it is affected by the mean error. This mean error can be particularly important when the boundaries are ignored because the detrended series are then not at all guaranteed to have a mean of zero. I thus consider several other properties of the error in measuring $y^{z}$ (or $y^{c}$ ) which are particularly relevant if one wants to use detrended series to study the properties of business cycles. To study these properties, I denote by $\hat{y}^{c}$ the estimated cycle, i.e, the difference between $y^{m}$ and the estimated trend in $y^{m}$. I then compute several statistics that illuminate the extent to which $\hat{y}^{c}$ and $y^{c}$ move together.

I first consider the correlation between $\hat{y}^{c}$ and $y^{c}$. This correlation is equal to about .94 for all specifications so the series largely move together regardless of the trend specification. To describe other properties of these co-movements, I consider regressions of $\hat{y}$ on $y^{c}$ and viceversa. The average $R^{2}$ of these regressions is close to the square of the average correlation of the two series, though the two are not identical because the correlation changes from realization to realization. The average $R^{2}$ is somewhat larger when the trend series are smoother, but the differences across trend specifications are very small.

The average regression coefficient in the regression of $\hat{y}^{c}$ on $y^{c}$ equals around .87. The fact that this is below 1 implies that the difference between $\hat{y}^{c}$ and $y^{c}$ is negatively correlated with $y^{c}$. By contrast, the average regression coefficient of $y^{c}$ on $\hat{y}^{c}$ is very close to 1 , so this error almost uncorrelated with $\hat{y}^{c}{ }^{12}$ This means that the best forecast of $y^{c}$ based on $\hat{y}^{c}$ is essentially equal to $\hat{y}^{c}$ itself, so this can be used directly as a measure of the cycle.

Since the correlation of $\hat{y}^{c}$ and $y^{c}$ is so high while, at the same time, $y^{z}$ is uncorrelated with $y^{c}$, the influence of the trend on the detrended series must be small. To obtain a more

\footnotetext{
${ }^{12}$ Note that the product of the two coefficients in Table 3 is close but not identical to the displayed $R^{2}$ of the regression of $\hat{y}^{c}$ on $y^{c}$. For a single regression, the two would be identical but here I am computing means of the coefficients and the $R^{2}$ 's of 500 regressions.
} 
direct estimate of this influence, it is attractive to look at first differences because the level of $y^{z}$ is nonstationary. I thus consider regressions of the change in $\hat{y}^{c}, \Delta \hat{y}^{c}$ on changes in the cycle $\Delta y^{c}$ and the trend $\Delta y^{z}$. The $R^{2}$ of the first of these regressions rises slightly as smoother trends are considered but these differences are tiny. Even in the case of the one sector model, this $R^{2}$ is so high that the correlation between $\Delta \hat{y}^{c}$ and $\Delta y^{c}$ is almost equal to .999 .

Similarly, the coefficient in this regression is estimated to be essentially equal to 1 . Thus, the changes in $\hat{y}^{c}$ are essentially all due to changes in $y^{c}$. Since these changes are independent of changes in $y^{z}$, one can use a regression of $\Delta \hat{y}^{c}$ on $\Delta y^{z}$ to obtain an estimate of the variance of $\Delta \hat{y}^{c}$ that is accounted for by the contemporaneous change in the trend $y^{z}$. This estimate is given by the $R^{2}$ displayed in table 3 just above the properties of fitted trend growth. Not surprisingly given the results in the regression of $\Delta \hat{y}^{c}$ on $\Delta y^{c}$, these $R^{2}$ 's are minuscule. As one would expect, they fall when the constructed trend is smoother, though, in any case, it seems fair to say that the effect of changes in technical progress on the estimated cycle are negligible.

While the focus of this paper is on the extent to which detrended series can be independent of technical progress, the question of whether fitted trends capture the effects of technical progress is also of interest. To study this question, I study the connection between changes in fitted trends, which I denote by $\Delta \hat{y}^{z}$ and changes induced by technical progress $\Delta y^{z}$. The $R^{2}$ 's of these regressions are substantially lower than those connecting fitted and actual cycles. Still, they are quite a bit larger in the case where $e^{I}=60$ than in the one sector model so that smooth trends do a better job of fitting the effect of technical progress when these effects are smoother. Similarly, there is a tendency for the estimated coefficients of the regressions of $\Delta y^{z}$ on $\Delta \hat{y}^{z}$ and vice-versa to have coefficients closer to 1 when $e^{I}=60$. However, both these $R^{2}$ 's and these coefficients suggest that the variations in the rate of growth of output induced by technical progress are only imperfectly captured by smooth trends. It remains an open question whether this fit can be improved significantly with better estimators or whether estimating the changes in GDP growth rates induced by smooth technical progress 
is intrinsically difficult.

At the bottom of table 3, I give two statistics that clarify why the MSE is higher when the series are detrended using the HP filter. In this case, the $R^{2}$ of the regression of $\hat{y}^{c}$ on $y^{c}$ is smaller so that these series are less closely related to one another. Moreover, the coefficient in this regression is smaller as well, implying that the series detrended by the HP filter move substantially less than one-for-one with $y^{c}$.

\section{The Smoothness of the effects of $\epsilon^{z}$ and the variabil- ity of markups}

The detrended series $\hat{y}^{c}$ are good estimates of $y^{c}$ in all the models I have considered. The models differ, however, in the extent to which efficiency wedges must vary to justify any particular movement in $y^{c}$. If one makes the trend smoother by increasing $e^{I}$, this makes firms less willing to vary employment in the investment goods sector. This means that certain changes in markups now have smaller effects on investment, so that larger markup changes are needed to ensure that investment (and even output) varies by the proper amount. I illustrate this in this section by considering the case where $\mu^{L}$ is constant. It is then important that variations in $\mu^{G}, \mu^{C}$ and $\mu^{I}$ be small enough so that markups of price over marginal cost fall only rarely below one. ${ }^{13}$

To study this question, I compute impulse responses of markups with respect to the shocks $\epsilon_{t}^{a}$ in (46). In effect, I am computing the way these markups vary as output evolves in the way described in Figure 3. The initial reaction of markups is, in effect, the size of the initial markup variations that is needed for GDP to rise by one percent under the assumption that subsequent markups will also vary in the way indicated by the impulse response function. As discussed earlier, these impulse responses are obtained by solving (20), (21), (22) and (23) in the case of the one-sector model while (40), (41), (42) and (43)

\footnotetext{
${ }^{13}$ One might be even more strict and require that they never fall below one. This would require that one depart from the linear framework that I consider here. On the other hand, it is worth noting that firms who wish to maintain a reputation for being reliable suppliers might well be willing to sell items for less than marginal cost on occasion.
} 
must be solved in the two-sector model.

Figure 13 reports two such impulse responses. The first corresponds to the responses in the one-sector model while the second involves the two-sector model with $e^{I}=.3$. Average markups charged by firms producing goods and services are assumed to equal 1.4 in both cases. Also, in two-sector model the markups in the consumption and investment goods sector are assumed to move in tandem so that $\nu^{C}$ equals 1 . Lastly, $\mu^{F}$ is assumed to be fixed and equal to one in both cases.

The resulting markup variations are quite similar in both cases and are nearly mirror images of the variations in $y^{c}$ displayed in Figure 3. In some ways the most disappointing aspect of the Figure is that the two dynamic responses are so similar. One might have expected the dynamic elements of the model, including the intertemporal substitution of consumption and labor supply to have larger qualitative effects. Instead, the period in which output is rising after the shock corresponds to a period where markups are falling whereas the later monotonic convergence of output to the steady state is accompanied by a similar convergence of markups.

Table 4 shows that, in the one sector model, the standard deviation of markup fluctuations $\sigma_{\mu}$ is somewhat larger than the standard deviation of movements in cyclical output, which equals .028. Not surprisingly given the results in Figure $13, \sigma_{\mu}$ is nearly $30 \%$ larger in the two-sector model than in the one-sector model. Table 4 also reports standard deviations for consumption and investment, and these are denoted by $\sigma^{C}$ and $\sigma^{I}$ respectively. For both of the specifications in Figure 13, the standard deviation of investment is substantially larger than that of consumption and this is broadly consistent with what has been repeatedly observed in the literature. I do not, in what follows, try to match these relative variabilities directly to those present in the data. Rather, I use the ratio of these standard deviations to discuss the effect of varying $e^{I}$, which plays a key role in keeping $y^{z}$ relatively smooth.

Table 4

The variability of markups, consumption and investment 


\begin{tabular}{|l|c|c|c|c|c|c|}
\hline Sectors & 1 & 2 & 2 & 2 & 2 & 2 \\
$e^{I}$ & & .3 & 5 & 5 & 5 & 60 \\
$\nu^{C}$ & & 1 & 1 & .3 & .4 & .15 \\
$\nu^{F}$ & & 0 & 0 & 0 & .1 & 1 \\
$\sigma_{\mu}$ & 0.035 & 0.045 & 0.075 & 0.198 & 0.146 & 0.397 \\
$\sigma^{C}$ & 0.014 & 0.018 & 0.036 & 0.026 & 0.025 & 0.027 \\
$\sigma^{I}$ & 0.081 & 0.057 & 0.011 & 0.034 & 0.036 & 0.035 \\
\hline
\end{tabular}

The next three columns of table 4 consider the case where $e^{I}=5$ while the last column considers a case where $e^{I}=60$. The qualitative response of markups is the same in all cases with an initial jump downwards in markups followed by further declines and then a monotonic convergence to the steady state. The specifications do differ in their quantitative implications, and these differences can be seen in the table.

When $\eta^{C}$ and $\eta^{F}$ are kept equal to 1 and zero respectively, raising $e^{I}$ to 5 has unappealing implications for the relative variability of consumption and investment. Because investment is now more costly to change, markups must vary a great deal more. With an average markup of 1.4, this increased variability poses little risk that prices will end up below marginal cost, however. What is more problematic is that the high cost of changing investment means that consumption is nearly three times more variable than investment.

It is possible to lower the relative variability of consumption by simply lowering the extent to which the markups on consumer goods $\mu^{C}$ vary. This is shown in the fourth column where I lower this variability by reducing $\nu^{C}$. This has two implications. the first is that it means that prices of investment goods must fall relative to the prices of consumption goods in booms. This is at least somewhat consistent with what is found in US data. The correlation between detrended GDP and the detrended ratio of the deflator for equipment investment to the deflator for nondurable consumption expenditures is -.28 when I use data from 1947 to 1998 .

The lowering of $\nu^{C}$ also requires that investment become more variable in order to keep the variability of $Y$ constant. This, in turn means that the volatility of $\tilde{\mu}^{I}$ must be raised again. The resulting standard deviation of $\tilde{\mu}^{I}$ is then high enough that there is nearly a $5 \%$ chance that markups fall below one even when the average markup is 1.4. 
The fifth column shows that, by raising $\nu^{F}$ to .1 , the variability of $\tilde{\mu}^{I}$ can be reduced while keeping constant the variability of $y^{c}$ and even raising slightly the ratio $\sigma^{I} / \sigma^{C}$. It is all the more remarkable that $\sigma^{I} / \sigma^{C}$ rises in this column given that I am increasing $\nu^{C}$ from .3 to .4. This means that variability in the efficiency of financial contracts can play a mayor role in explaining cyclical fluctuations.

Temporary changes in $\mu^{F}$ do not have strong implications for aggregate output. As stressed by Cooper and Ejarque (1994), an increase in $\mu^{F}$ discourages investment (because contracts for borrowing become expensive) while encouraging consumption (because returns on savings are temporarily depressed). Having this occur when markups on goods and services are already high so that output is low ensures that investment falls relative to consumption at these times. This increases the volatility of investment relative to that of consumption and thus reduces the need to make $\tilde{\mu}^{I}$ variable relative to $\tilde{\mu}^{C}$. Interestingly, this pattern of variability of $\mu^{F}$ fits with the idea that monetary policy affects the economy not only through its effect on interest rates but also through its effects on the efficiency of the financial system. As in the sticky price models like Rotemberg and Woodford (1997), tight monetary policy might reduce output because markups rise as a result of price rigidity. However, the disproportionate effect of this on investment may be due in part to the fact that the financial contracts market is less efficient at these times. Note that the changes in the margins on financial contracts required by this specification are only one tenth the size of the required changes in $\tilde{\mu}^{I}$. Thus, the average value of $\mu^{F}$ need not be particularly large and the behavior of the economy may be well approximated by linearizing around the point where $\mu^{F}$ equals one.

The last column shows that attractiveness of specifications with very high values of $e^{I}$ is limited, even though these make $y^{z}$ smoother. When $e^{I}$ equals 60 , the standard deviation of $\tilde{\mu}^{I}$ must be nearly .4 even if $\nu^{F}$ is raised to the empirically implausible value of 1 . To keep the ratio of $\sigma^{I} / \sigma^{C}$ greater than one, the volatility of $\tilde{\mu}^{I}$ must be raised further if $\nu^{F}$ is lowered. This section has thus shown that there is a tradeoff between raising $e^{I}$ to raise the accuracy of smooth trends as estimators of $y^{z}$ and limiting the volatility of efficiency wedges 
that is needed to explain cyclical fluctuations.

This finding covers only situations where inefficiency wedges are responsible for cyclical movements in GDP. However, it is quite possible that the findings would extend to alternate models of cyclical fluctuations. The reason is that high values of $e^{I}$ prevent investment from fluctuating. This has the advantage of increasing the smoothness of the response of investment to news about future productivity growth and thereby improves the accuracy of smooth trends as estimators of the effect of smooth technical progress. On the other hand, it presumably tends to reduce the effect of all shocks on investment. Thus, high values of $e^{I}$ may make it necessary for firms to be provided with quite variable incentives for investment to ensure that cyclical investment remains more volatile than cyclical consumption.

\section{Conclusion}

Shocks that lead to gradual and prolonged increases in productivity do not generate perfectly smooth changes in output because they create strong wealth effects. However, one can explain the size of long term changes in US GDP growth rates with only small shocks of this type. This means that fairly smooth paths for GDP result from shocks of this sort when their size is empirically plausible. The results is that smooth trends measure fairly well the effect of this technical progress on GDP and, by the same token, detrended GDP is mostly affected by disturbances whose effect is only transitory.

GDP growth can presumably be made smoother still in response to changes in technical progress by considering less standard models. In particular, it may be possible to reduce the size of the shocks to perceived wealth that accompany innovations that lead to gradual changes in the productivity. One method for doing so is to change the way information about these innovations is released in the economy. In this paper, I have supposed that information about the permanent effect of these shocks is released all at once, at the moment when these shocks have their first, negligible impact. It may be more empirically appealing to imagine that this information is released gradually. In particular, some individuals may know about the permanent effects of certain technical breakthroughs before others so that the wealth 
revisions of different individuals may be staggered over time. The result might be an even smoother response of GDP to these shocks. It is important to stress, however, that these modelling changes do not seem to be necessary for obtaining a coherent framework where detrended GDP is essentially independent of technical progress. 


\section{$7 \quad$ References}

Beaudry, Paul and Franck Portier, "An Exploration into Pigou's Theory of Cycles," mimeo, November 2000.

Bernanke, Ben S., Mark Gertler and Simon Gilchrist, "The Financial Accelerator in a Quantitative Business Cycle Framework,"in Taylor, John B. and Michael Woodford eds. Handbook of Macroeconomics, Amsterdam: Elsevier, 1999.

Cogley, Timothy and James M. Nason, "Output Dynamics in Real Business Cycle Models," American Economic Review, 85, June 1995, pp. 492-511.

Cooper, Russell and Joāo Ejarque, "Financial Intermediation and Aggregate Fluctuations: A Quantitative Analysis," NBER Working Paper 4819, August 1994

Gali, Jordi, "Monopolistic Competition, Business Cycles, and the Composition of Aggregate Demand," Journal of Economic Theory, 63, June 1994, pp. 73-96.

— "Technology, Employment, and the Business Cycle: Do Technology Shocks Explain Aggregate Fluctuations?," American Economic Review, 89, March 1999, pp. 24971.

Gali, Jordi, Mark Gertler and J. David Lopez-Salido, "Markups, Gaps, and the Welfare Costs of Business Fluctuations," NBER Working Paper 8850, March 2002.

Greenwood, Jeremy, Zvi Hercowitz and Gregory W. Huffman, "Investment, Capacity Utilization and the Real Business Cycle," American Economic Review, 78, June 1988, pp. 402-17.

Helpman, Elhanan and Manuel Trajtenberg, "A Time to Sow and a Time to Reap: Growth Based on General Purpose Technologies," in Helpman, Elhanan, ed. General Purpose Technologies and Economic Growth, Cambridge, MA: MIT Press, 1998.

King, Robert G., Charles I. Plosser and Sergio Rebelo, "Production, Growth and Business Cycles, I. The Basic Neoclassical Model," Journal of Monetary Economics, 21, March/May 1988a, pp. 195-232.

King, Robert G. and Sergio Rebelo, "Resuscitating Real Business Cycles," in Taylor, John B. and Michael Woodford eds. Handbook of Macroeconomics, Amsterdam: Elsevier, 1999.

Manuelli, Rodolfo E., "Technological Change, the Labor Market and the Stock Market," NBER Working Paper 8022, November 2000 
Mansfield, Edwin, The Economics of Technological Change, New York: Norton, 1968.

Prescott, Edward C., "Theory ahead of Business Cycle Measurement," Federal Reserve Bank of Minneapolis Quarterly Review, Fall 1986, 9-22.

Rotemberg, Julio and Michael Woodford, "Markups and the Business Cycle,", Macroeconomics Annual, 1991.

- "Real Business Cycle Models and the Forecastable Movements in Output, Hours and Consumption ," American Economics Review, 86, March 1996, 71-89.

- "An Optimization-Based Framework for the Evaluation of Monetary Policy," NBER Macroeconomics Annual, 1997, pp. 297-345.

Shea, John, "What do Technology Shocks Do?" NBER Macroeconomics Annual, 1998, pp. 275-310. 
Table 3

Indicators of Accuracy of Trend/Cycle Decomposition

\begin{tabular}{|c|c|c|c|c|}
\hline & One-sector & \multicolumn{3}{|c|}{ Two-sector } \\
\hline & & $e^{I}=.3$ & $e^{I}=5$ & $e^{I}=60$ \\
\hline MSE of fitted trend & $1.30 \mathrm{e}-4$ & $1.33 \mathrm{e}-4$ & $1.26 \mathrm{e}-4$ & $1.25 \mathrm{e}-4$ \\
\hline $\begin{array}{l}\text { MSE of fitted trend } \\
\text { (full sample) }\end{array}$ & $1.80 \mathrm{e}-4$ & $1.84 \mathrm{e}-4$ & $1.72 \mathrm{e}-4$ & $1.70 \mathrm{e}-4$ \\
\hline \multicolumn{5}{|l|}{ Properties of fitted cycle } \\
\hline $\begin{array}{l}\text { Correlation of actual } \\
\text { and fitted cycle }\end{array}$ & 0.939 & 0.938 & 0.943 & 0.943 \\
\hline $\begin{array}{l}R^{2} \text { in regression of } \\
\text { fitted on actual cycle }\end{array}$ & .884 & .881 & .891 & .892 \\
\hline $\begin{array}{l}\text { Coefficient in regression of } \\
\text { fitted on actual cycle }\end{array}$ & .872 & .872 & .874 & .874 \\
\hline $\begin{array}{l}\text { Coefficient in regression of } \\
\text { actual on fitted cycle }\end{array}$ & 1.017 & 1.014 & 1.022 & 1.0123 \\
\hline $\begin{array}{l}R^{2} \text { in regression of } \Delta \hat{y}^{c} \\
\text { on } \Delta y^{c}\end{array}$ & .998 & .997 & .998 & .999 \\
\hline $\begin{array}{l}\text { Coefficient in regression of } \Delta \hat{y}^{c} \\
\text { on } \Delta y^{c}\end{array}$ & .999 & .999 & .999 & .999 \\
\hline $\begin{array}{l}R^{2} \text { in regression of } \Delta \hat{y}^{c} \\
\text { on } \Delta y^{z}\end{array}$ & .002 & .003 & .002 & .001 \\
\hline \multicolumn{5}{|c|}{ Properties of fitted trend growth } \\
\hline $\begin{array}{l}R^{2} \text { in regression of } \Delta \hat{y}^{z} \\
\text { on } \Delta y^{z}\end{array}$ & 0.592 & 0.523 & 0.649 & 0.657 \\
\hline $\begin{array}{l}\text { Coefficient in regression of } \Delta \hat{y}^{z} \\
\text { on } \Delta y^{z}\end{array}$ & 0.649 & 0.562 & 0.742 & 0.758 \\
\hline $\begin{array}{l}\text { Coefficient in regression of } \Delta y^{z} \\
\text { on } \Delta \hat{y}^{z}\end{array}$ & 2.59 & 1.39 & 2.58 & 1.81 \\
\hline \multicolumn{5}{|l|}{ Properties of the HP filter } \\
\hline $\begin{array}{l}\text { MSE of HP filter } \\
\text { (full sample) }\end{array}$ & $3.15 \mathrm{e}-4$ & $3.15 \mathrm{e}-4$ & $3.15 \mathrm{e}-4$ & $3.15 \mathrm{e}-4$ \\
\hline MSE of HP filter & $2.95 \mathrm{e}-4$ & $2.95 \mathrm{e}-4$ & $2.95 \mathrm{e}-4$ & $2.95 \mathrm{e}-4$ \\
\hline $\begin{array}{l}R^{2} \text { in regression of } \\
\text { fitted on actual cycle }\end{array}$ & .698 & .698 & .699 & .699 \\
\hline $\begin{array}{l}\text { Coefficient in regression of } \\
\text { fitted on actual cycle }\end{array}$ & .583 & .583 & .583 & .583 \\
\hline
\end{tabular}


Figure 1:

The rate of growth of US trend GDP

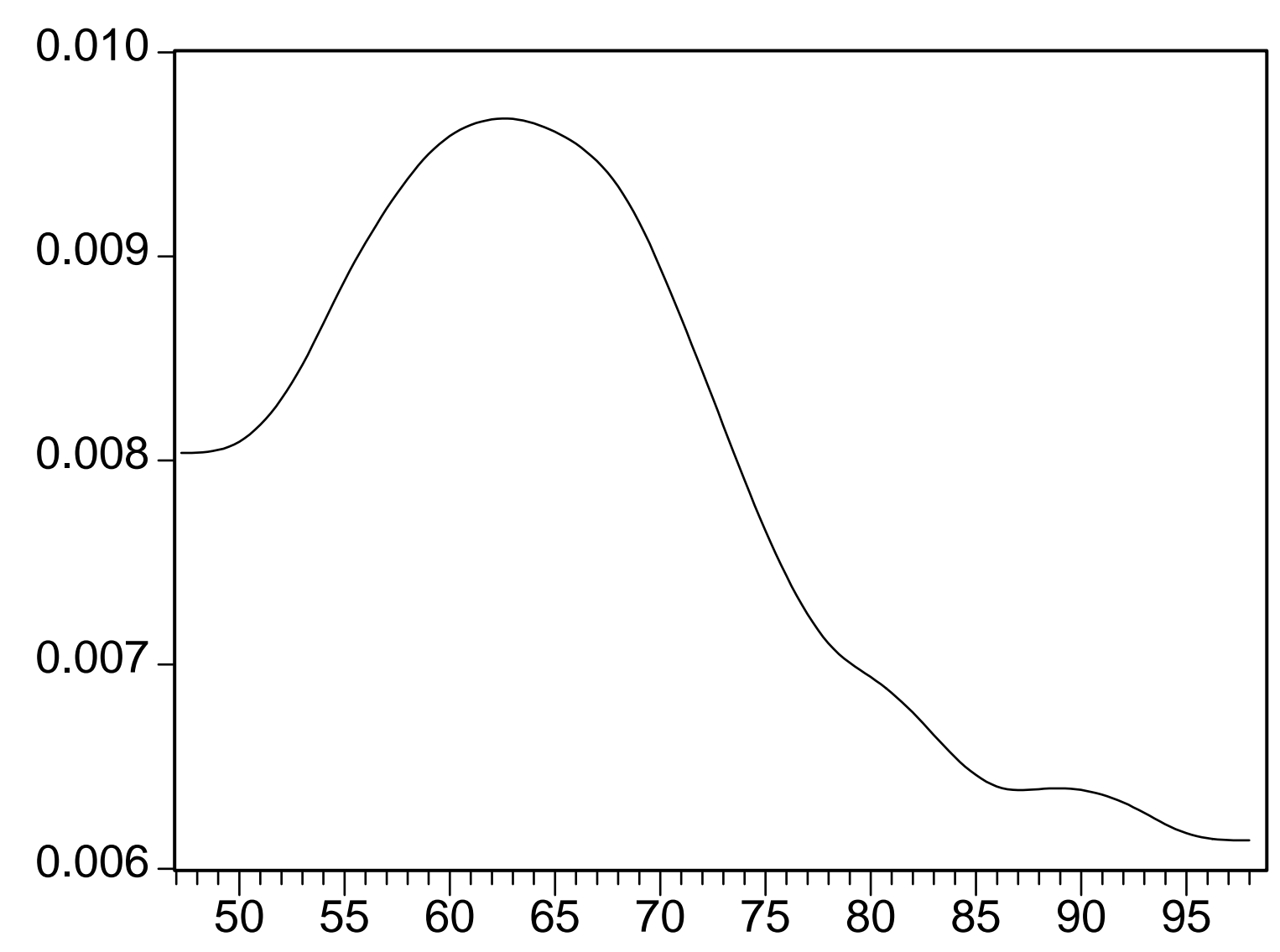


Figure 2:

Response of trend US GDP growth to unit impulse in $A R(5)$

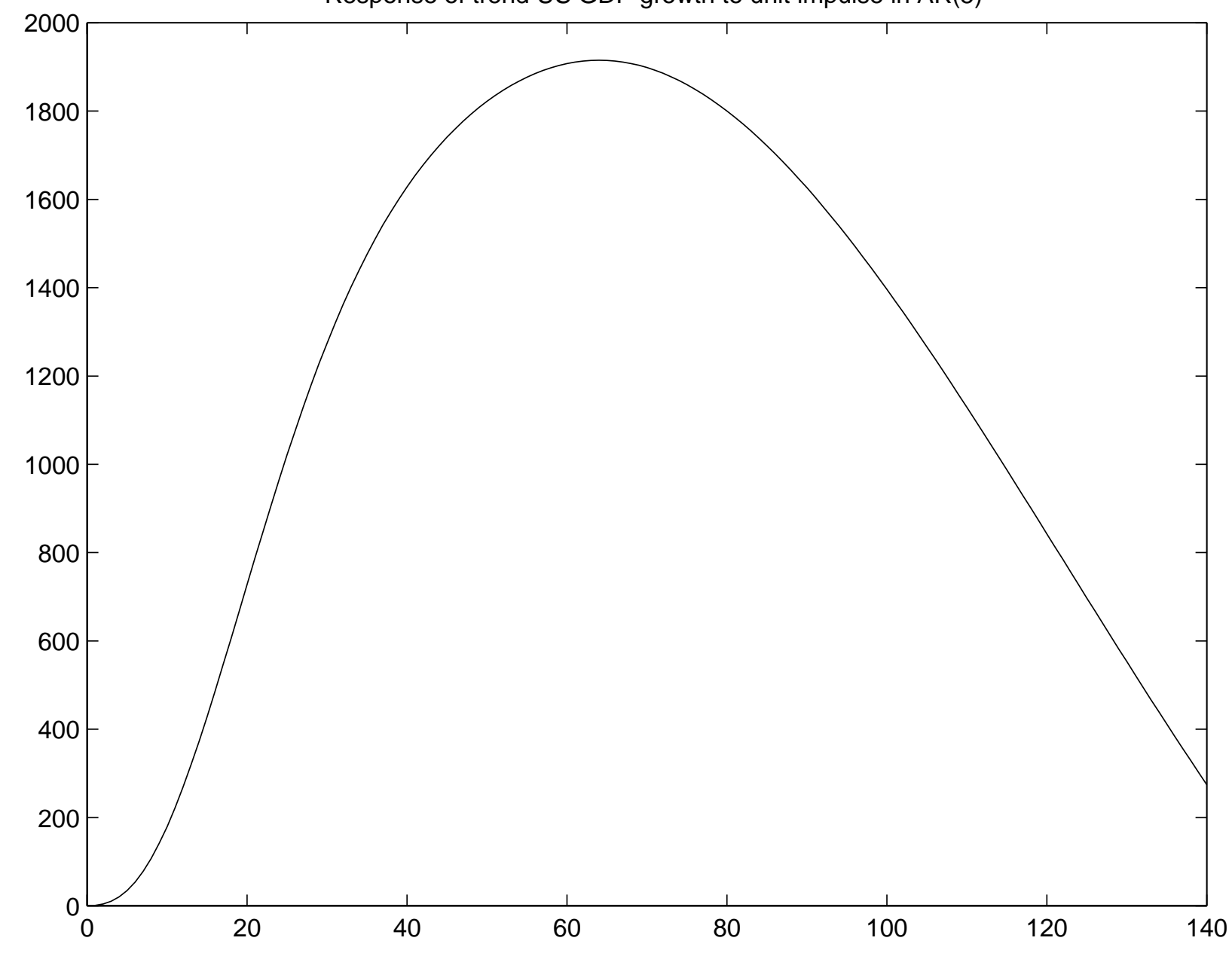


Figure 3:

Response of detrended US GDP (level) to a unit impulse

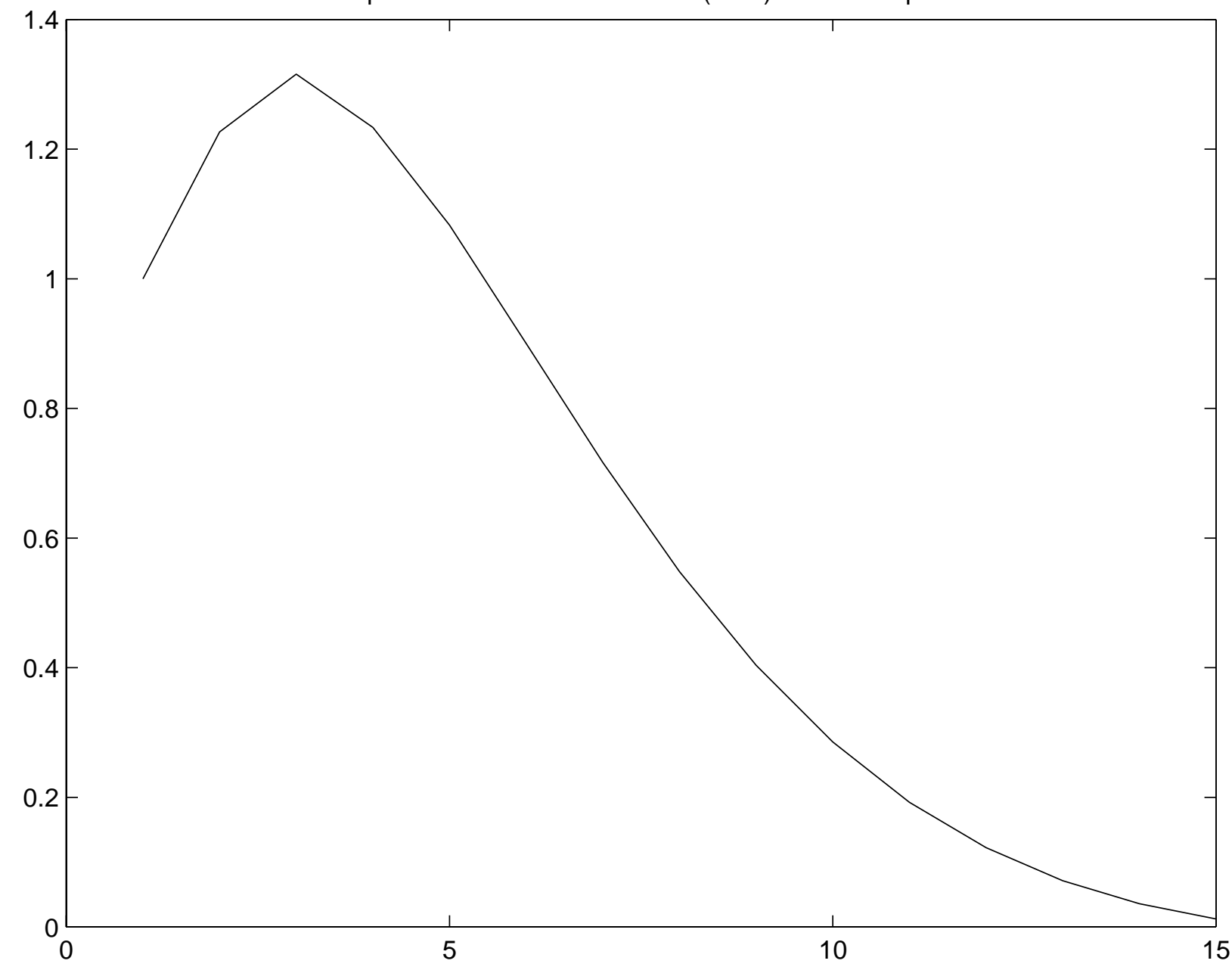


Figure 4:

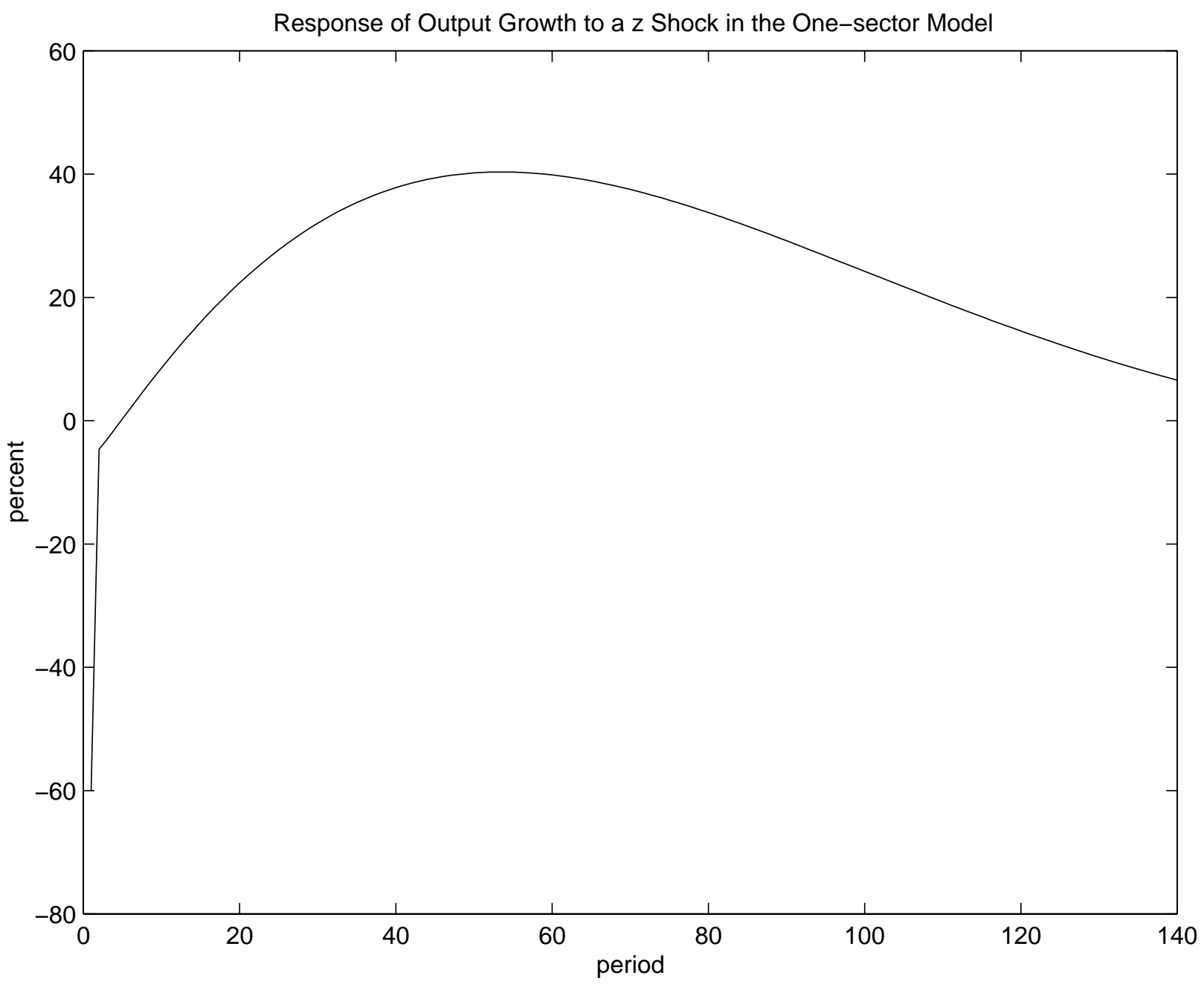


Figure 5:

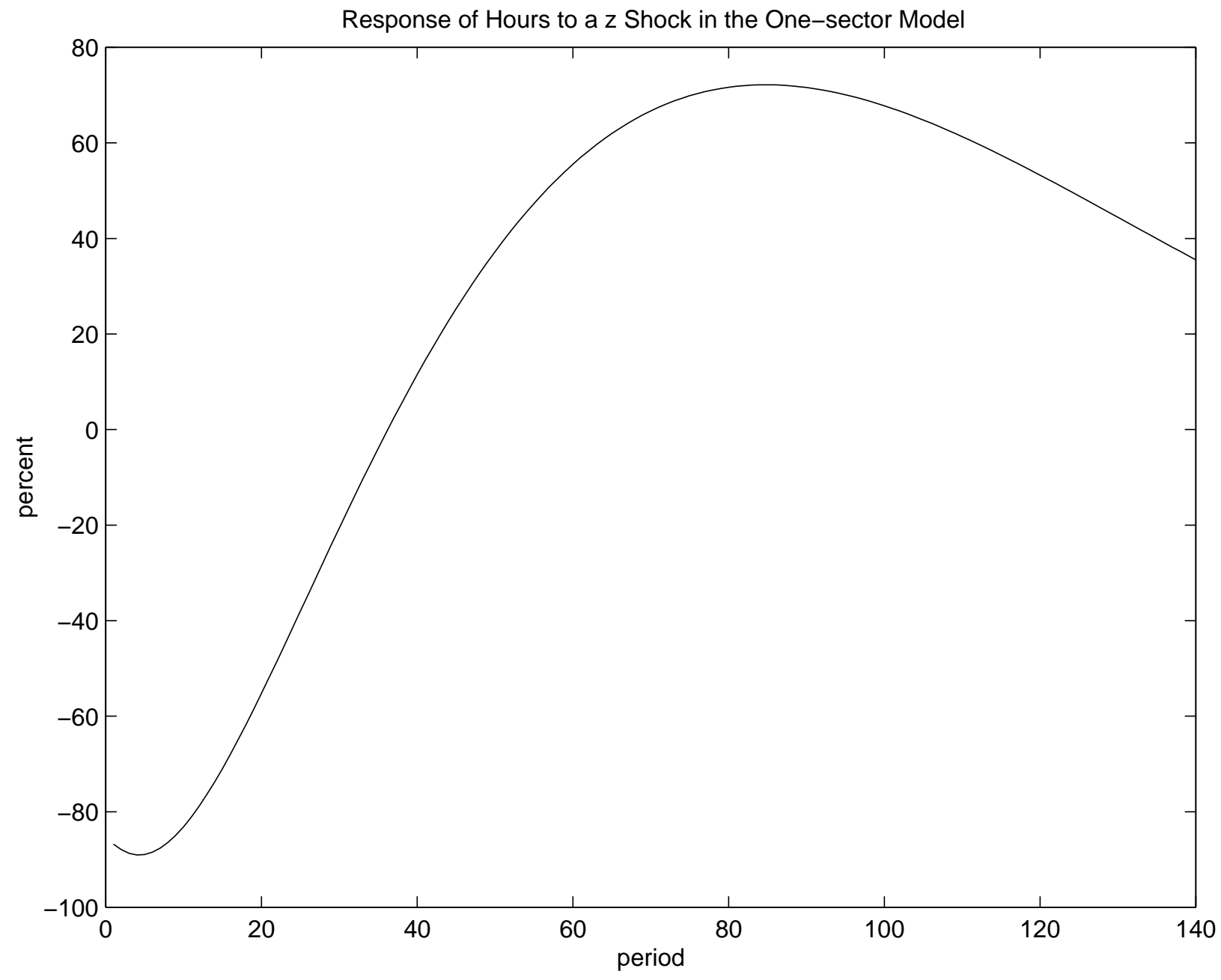


Figure 6:

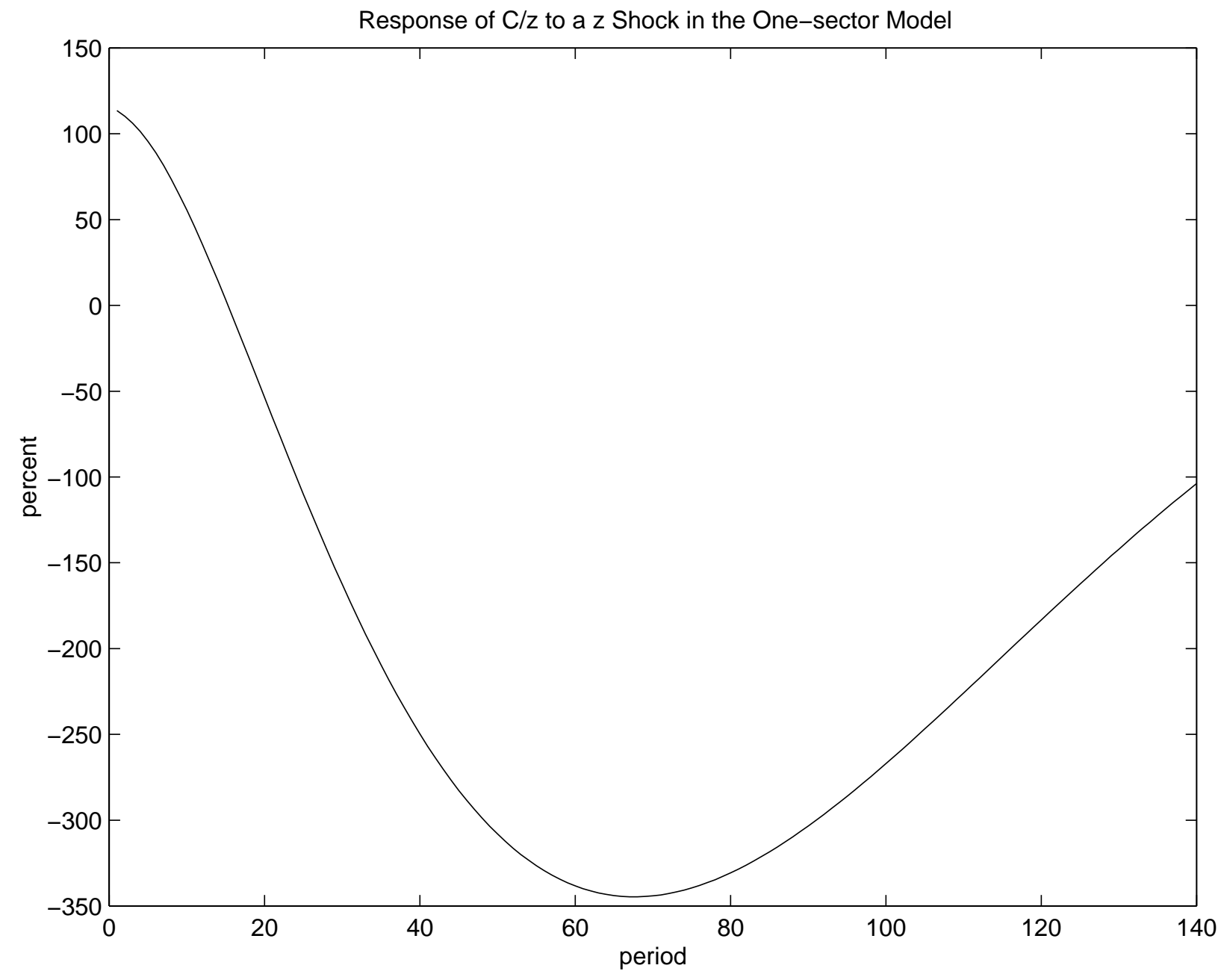


Figure 7:

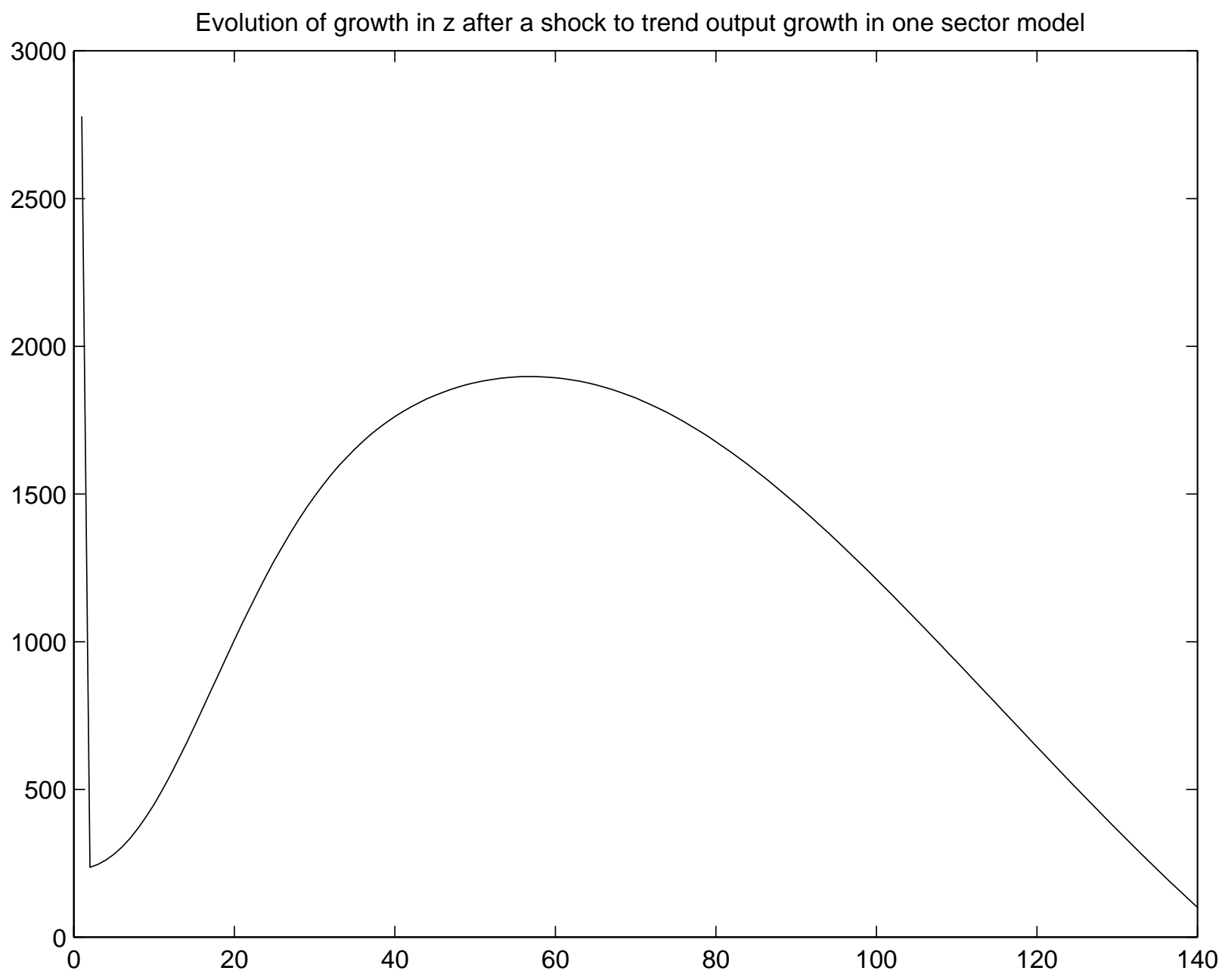


Figure 8:

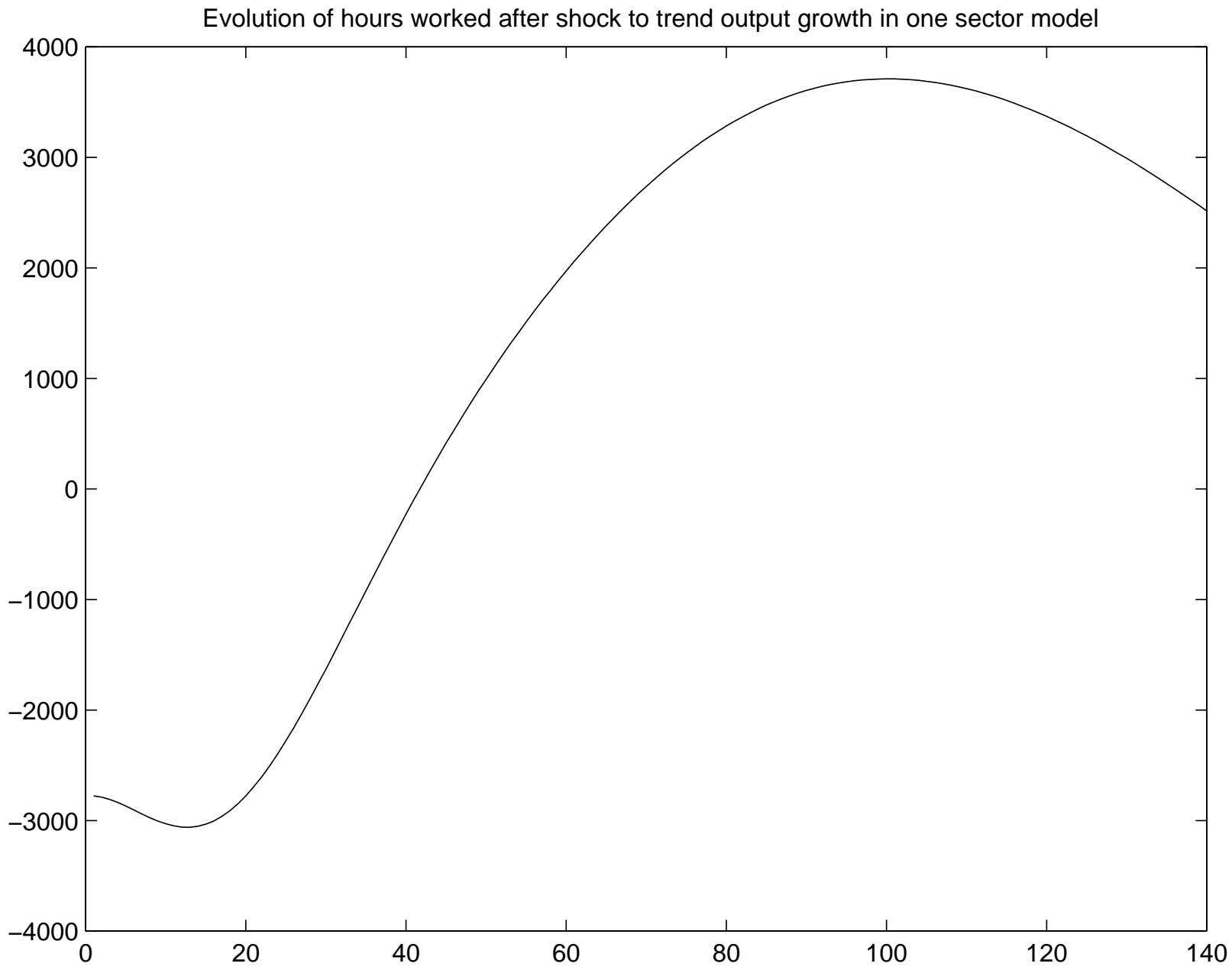


Figure 9:

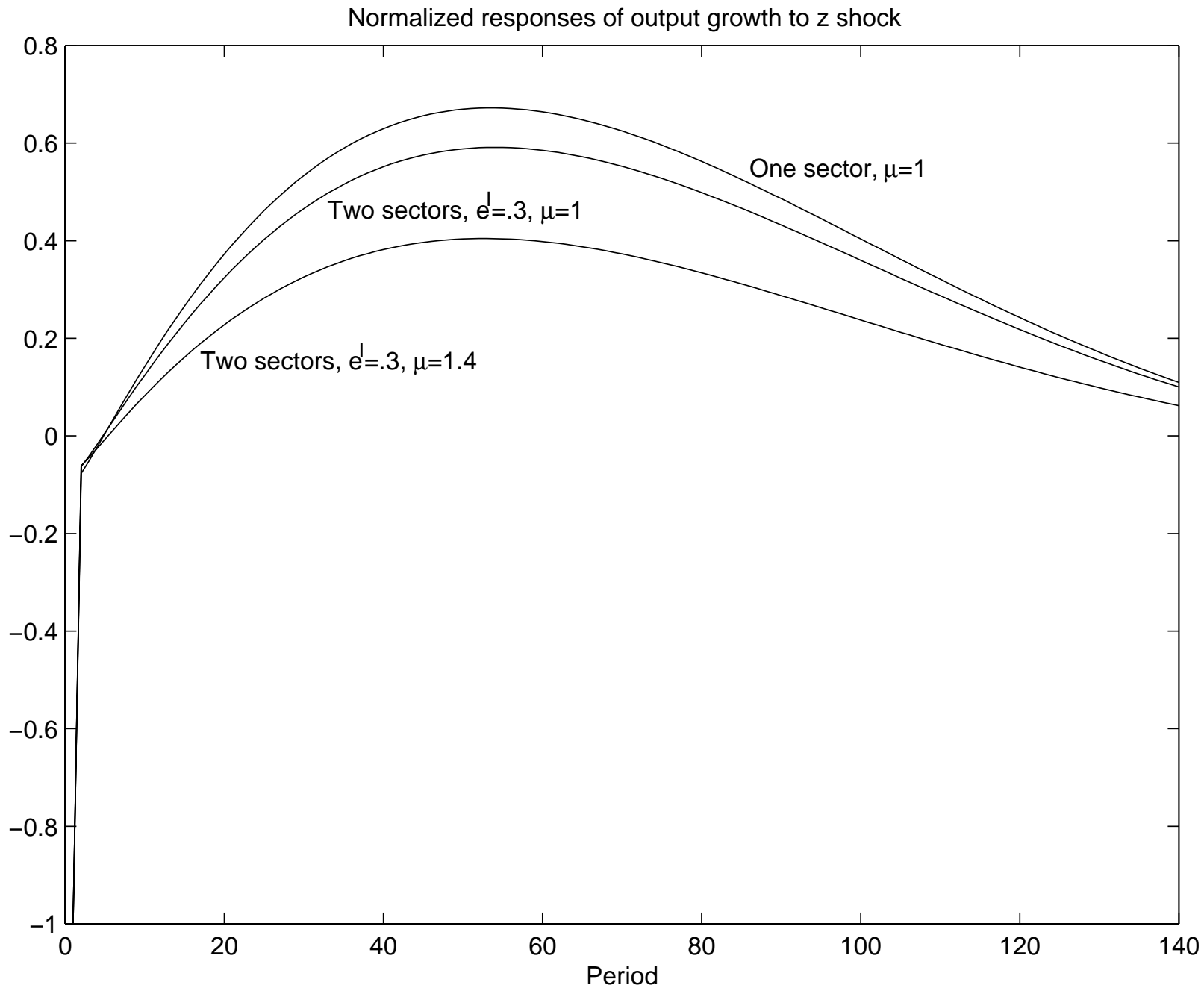


Figure 10:

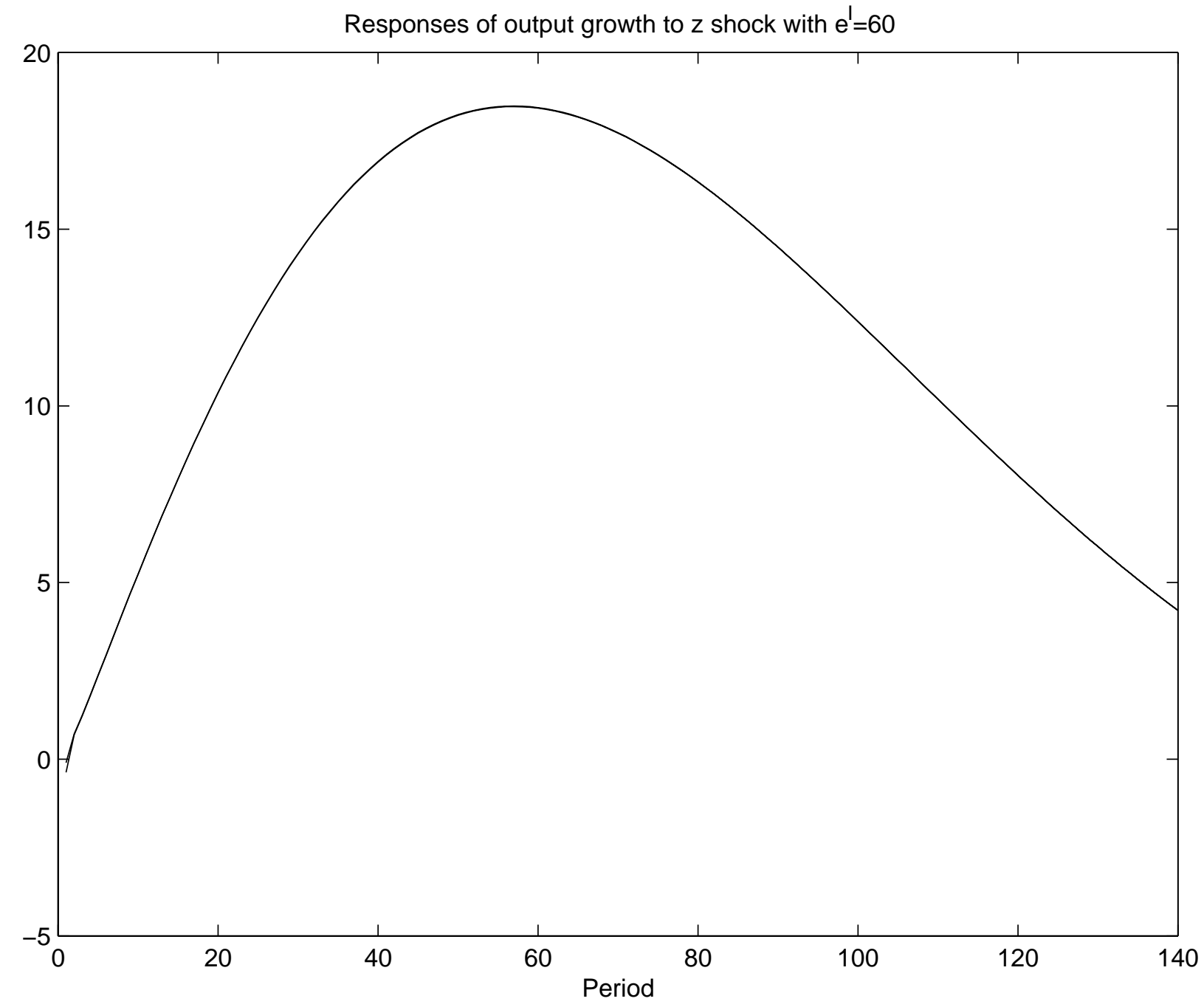


Figure 11:

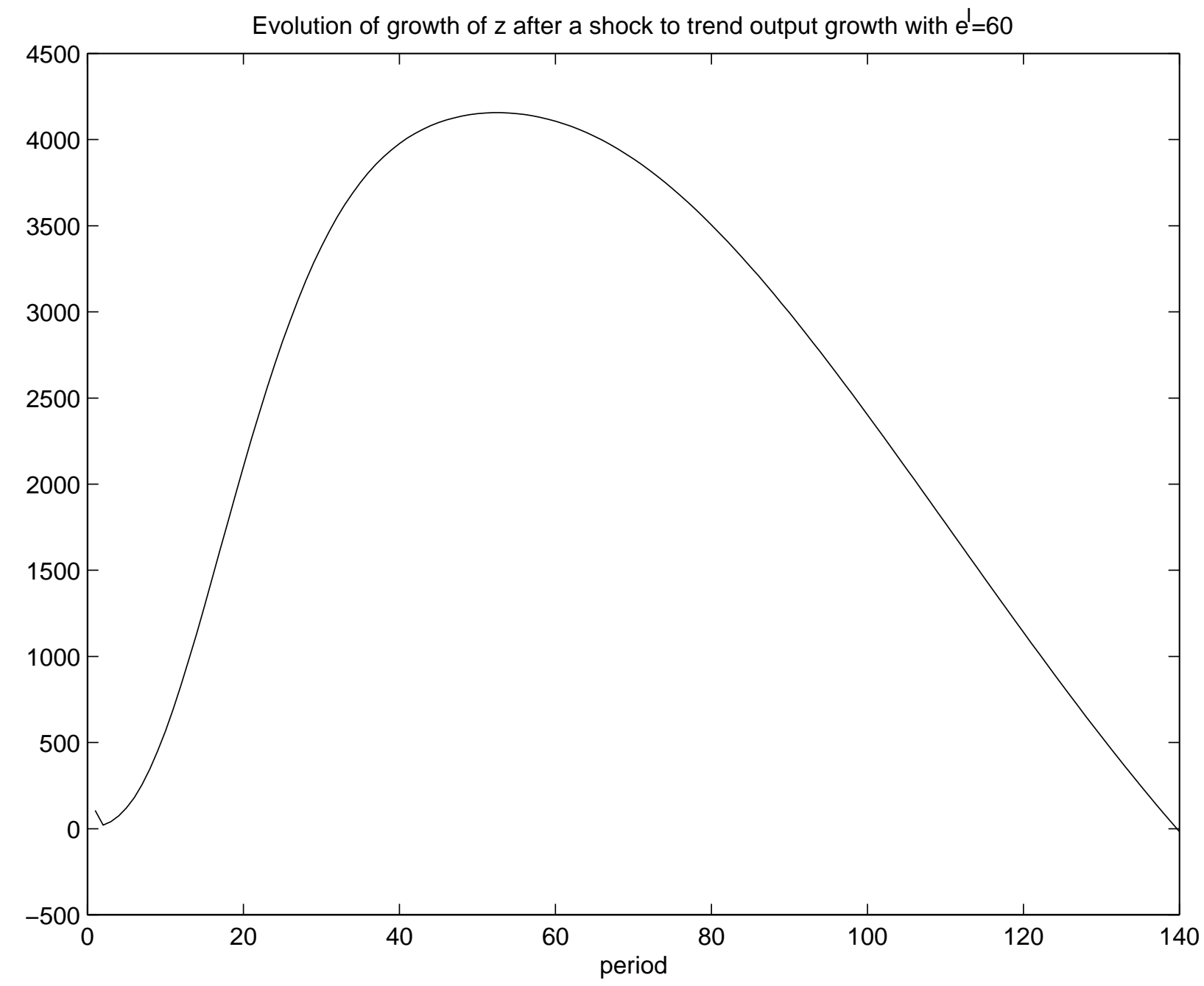


Figure 12:

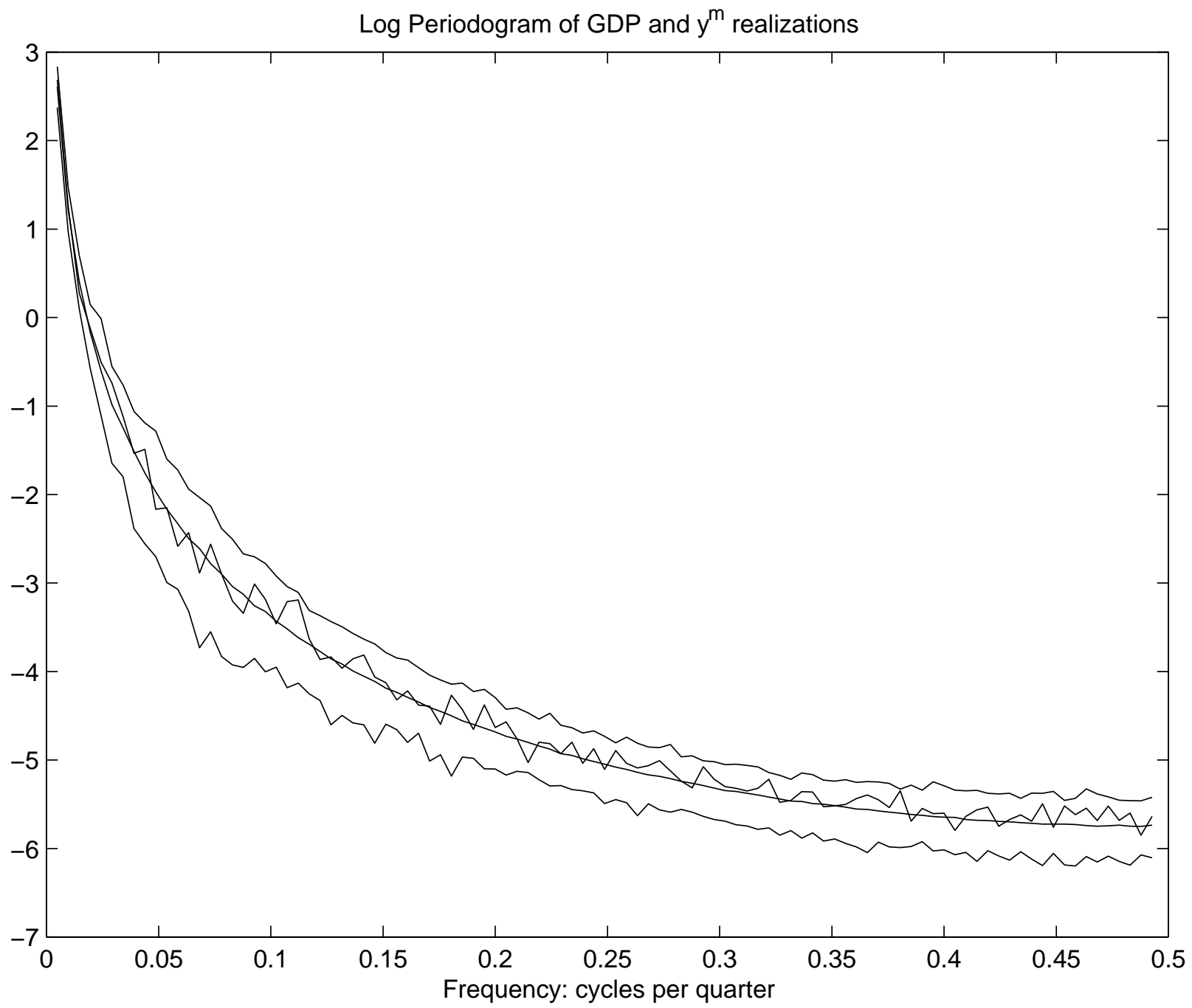


Figure 13:

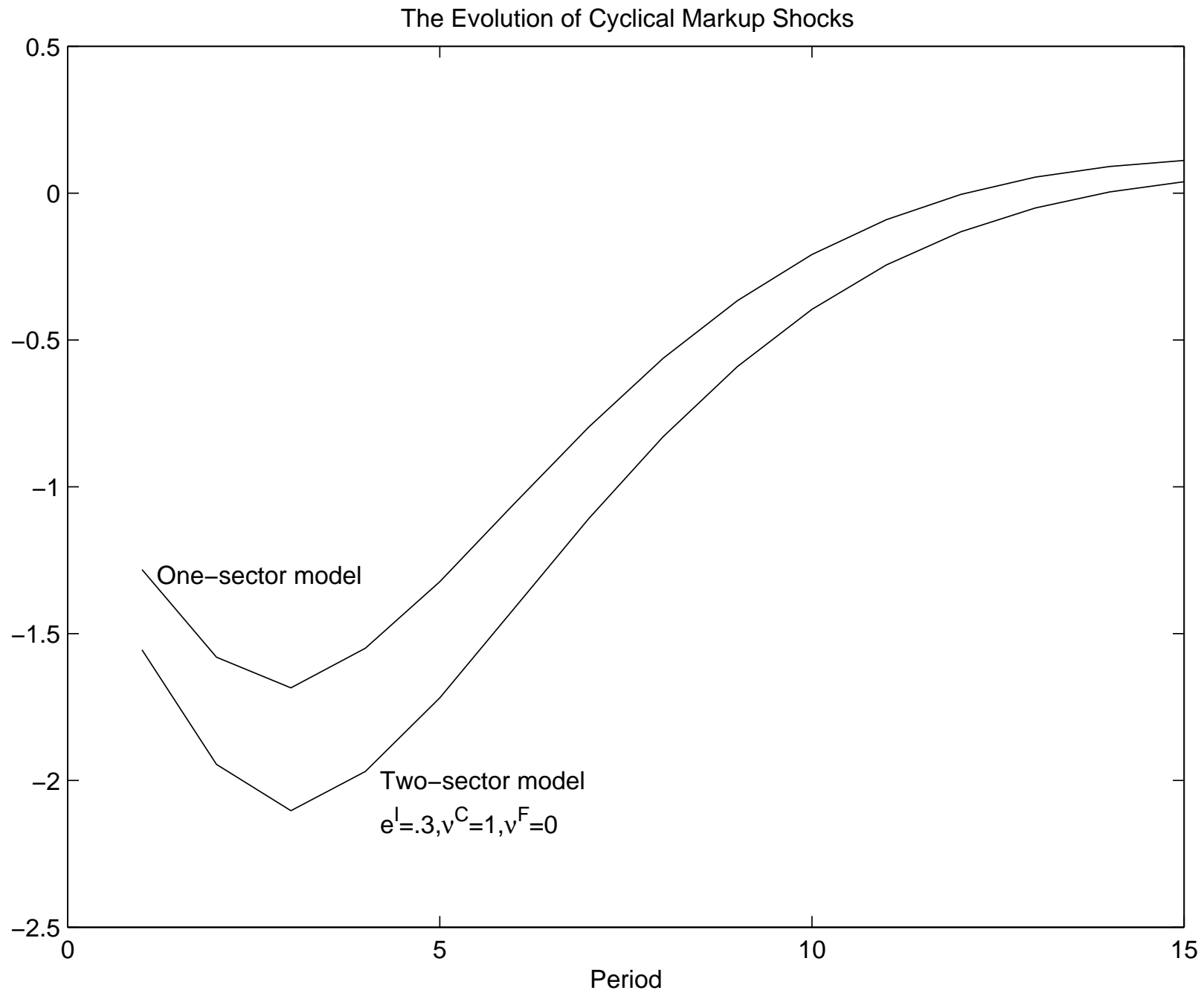

